المجلة الدولية للدراسات القانونية والفقهية المقارنة

بحث رقم 4

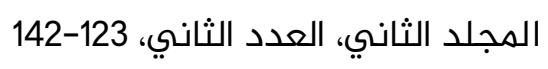

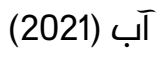

\title{
وسائل الإثبات الإلكترونية أمام \\ القضاء الإداري
}

\section{عدي محمد علي الهيلات}

باحث دكتوراة في كلية الحقوق- جامعة ابن زهر المغربية

ومحامي متدرب لدى نقابة المحامين الأردنيين

odaihailat1991@gmail.com

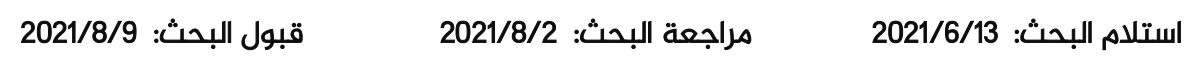

DOI: https://doi.org/10.31559/LCJS2021.2.2.4

(c) (1) This file is licensed under a Creative Commons Attribution 4.0 International 
www.refaad.com
المجلة الدولية للدراسات القانونية والفقهية المقارنة

International Journal of Legal and Comparative Jurisprudence Studies (LCJS)

Journal Homepage: https://www.refaad.com/views/LCJS/Home.aspx

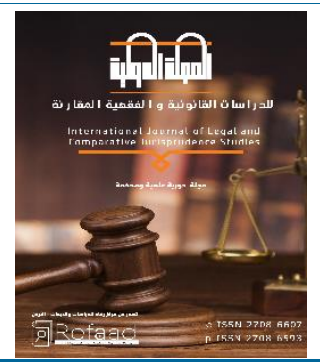

وسائل الإثبات الإلكترونية أمام القضاء الإداري

\author{
عدي محمد علي الهيلات \\ باحث دكتوراة في كلية الحقوق- جامعة ابن زهر المغربية \\ ومحامي متدرب لدى نقابة المحامين الأردنيين \\ odaihailat1991@gmail.com
}

DOI: https://doi.org/10.31559/LCJS2021.2.2.4 2021/8/9 2021/6/13 مراجعة البحث: 2021/8/2 قبول البحث البحث: 201/2

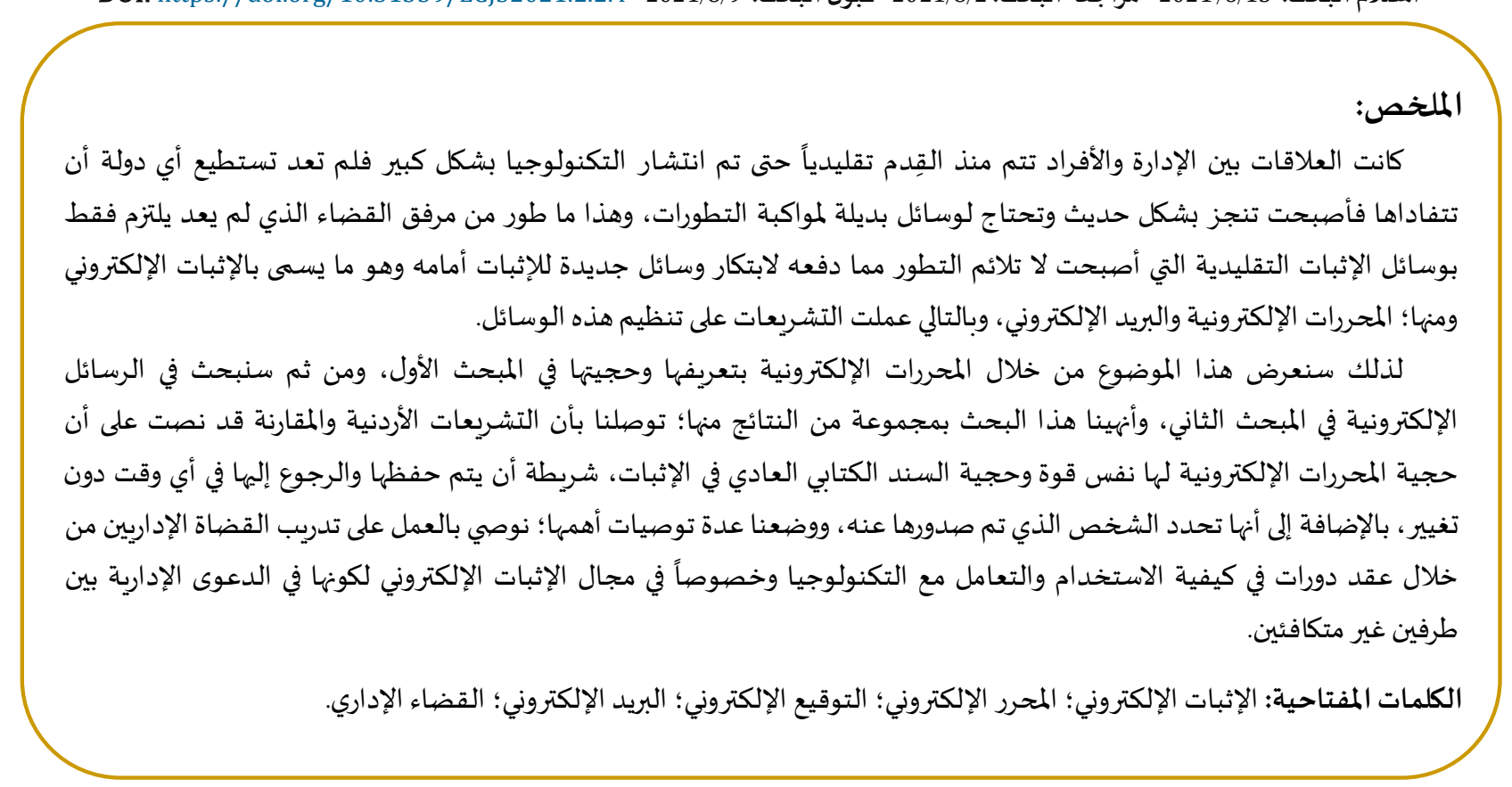

المقدمة:

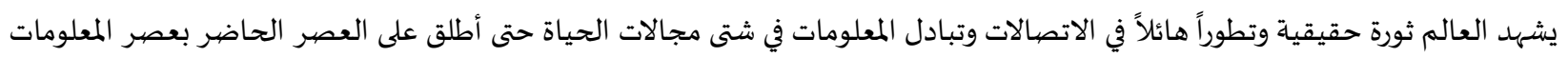

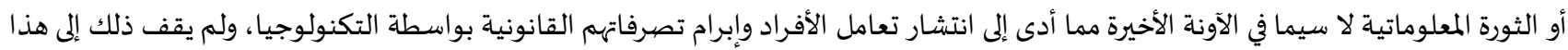

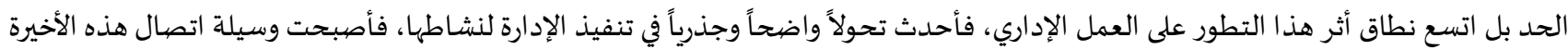

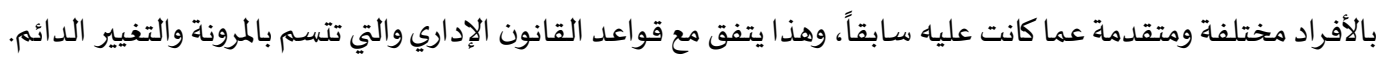

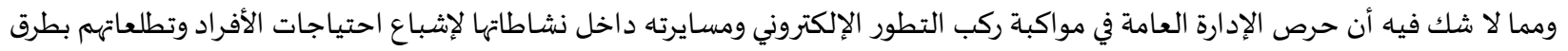

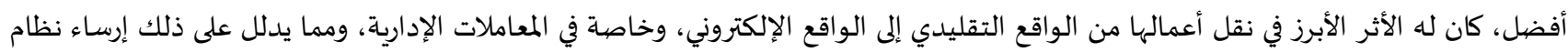

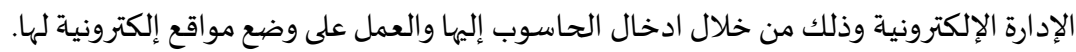

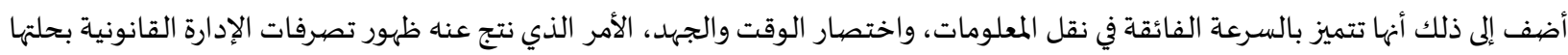
الجديدة ومنها القرارات الإدارية الإلكترونية والعقد الإداري الإلكتروني. 
وأكد المشرع الأردني على هذه التطورات وما صاحبها من استخدام الوسائل الإلكترونية لإتمام وتنفيذ المعاملات الإدارية، وهو ما يتجلى في قانون

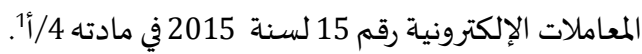

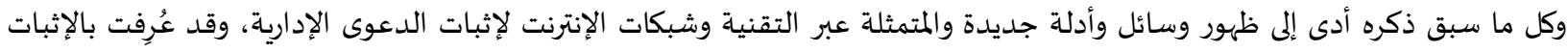

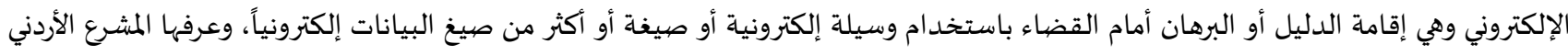
أيضاً بأنها: " تقنية استخدام وسائل كهربائية أو مغناطيسية أو ضوئية أو كهرومغناطيسية أو أي وسيلة مشابهة ".

أهمية الدراسـة:

وأهمية هذا الموضوع تكمن من خلال التسهيل على القاضي الإداري بواسطة توفير الجهد والوقت، علاوة على قلة المراجع في هذا الموضوع وخصوصاً أنه متعلق في القضاء الإداري مما يضفي علئ هذيه أهمية كبيرة من خلال الاستعانة بهاه من قِبل الفقهاء والباحثين، وأيضاً الدوافع الرئيسية

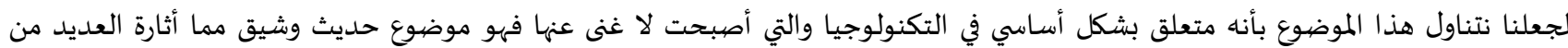
الخلافات بين الفقهاء والقضاء الإداري، ومساندة حقوق المتقاضي من خلال هذه الوسائل. أهداف الدراسـة: لقد أثار هذا الموضوع العديد من الإشكاليات والتساؤلات خصوصاً أنه حديث الظهور مما جعل التشريعات والفقه متأخر إلى حد ما في مواكبته

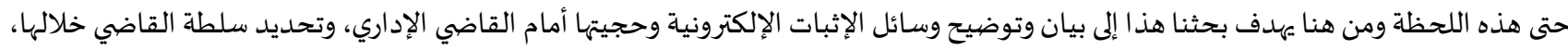
وكما تهدف للإجابة على تساؤلات الدراسة واشكالياتها للوصول إلى توصيات تعالج موضوع البحث بشكل متكامل.

إشكالية الدراسـة وصعوباتها: تكمن مشكلة البحث في مدى معالجة المشرع الأردني للوسائل الإلكترونية بشكل كامل وبكافة جوانها القانونية وبالتالي حماية حقوق الأفراد عند

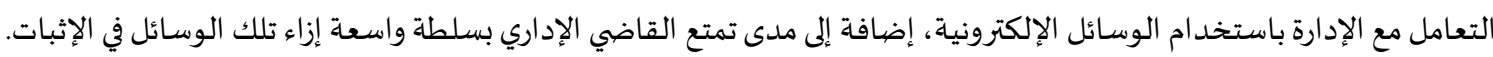

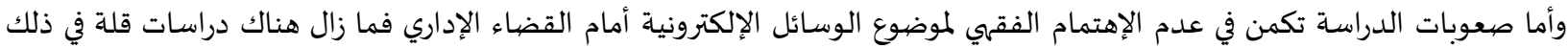
ونتمنى أن يتم وضعها على شكل رسالة ماجستير أو اطروحة دكتوراة، أضف إلى ذلك ندرة الأحكام القضائية الإدارية فيها. تساؤلات الدراسـة:

تأتي دراستنا هذه للإجابة على جميع التساؤلات التي سنطرحها وهي:

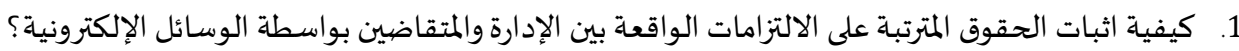

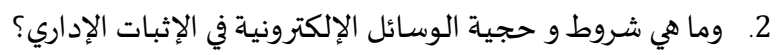

3. وما مدى سلطة القاضي الإداري إزاء هذه الوسائل في قبولها أو عدمها وخاصية في ظل غياب تشريع خاص الإسبات بالإثبات الإداري؟

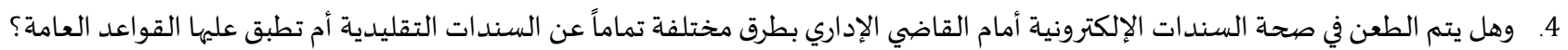

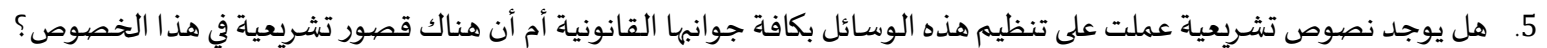

للحديث أكثر عن هذا الموضوع، قسم الباحث هذا البحث إلى مبحثين؛ نبحث عن المحررات الإلكترونية، ومن ثم الرسائل الإلكترونية في المبحث

\section{المبحث الأول: المحررات الإلكترونية كوسيلة الإثبات الإداري}

يعتبر الدليل الكتابي الخطي والموثق بتوقيع تقليدي أعلى مرتبة بين أدلة الإثبات؛ لما يوفره من ثقة وثبات لا توجد لدى الوسائل الأخرى ويتصف

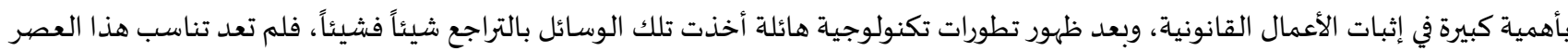

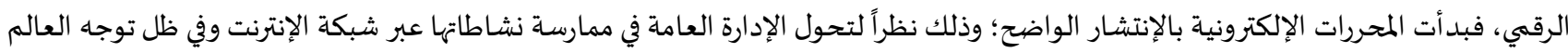

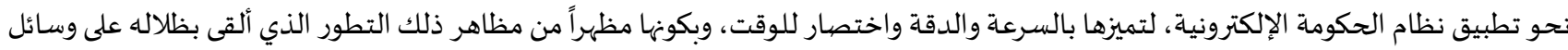
الإثبات. وتأسيساً على ما سبق ولمواكبة ما نتج عن التقدم التكنولوجي من تغيير في مفههوم الدليل الكتابي أدى ذلك إلى تدخلاً تشريعياً في أغلب دول العالم؛

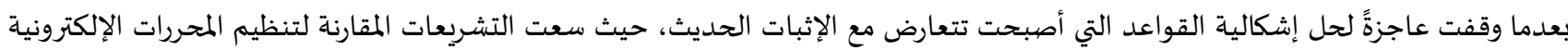

1 قانون المعاملات الإلكترونية رقم 15 لسنة 2015، الصادر في عدد الجريدة الرسمية رقم 5341، بتاريخ 201/5/17، ص5292. 
وجعلها متوازية مع الكتابة الورقية في الإثبات، على الرغم بأهها لا تزال غير قادرة على ملاحقة تلك التطورات، وفي الوقت الحالي تم التوسع في استخدام تلك المحررات في مواجهة وباء كورونا. وأخيراً لا بد أن نوضح بأن الكتابة الإلكترونية تختلف تماهاء

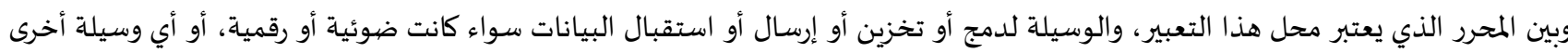

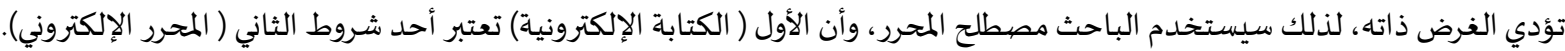

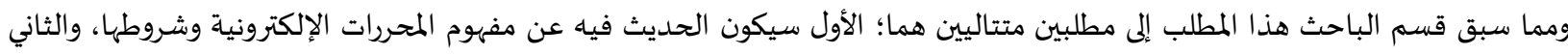
سنوضح حجية المحرر الإلكتروني كما يلي:

المطلب الأول: مفهوم المحررات الإلكترونية سنتناول تعريف المحررات الإلكترونية من ناحية الفقه والتشروئه الإنيه وتقييمنا كما يلي:

$$
\text { الفرع الأول: التعريف الفقهي للمحررات الإلكترونية }
$$

ذهب بعض الفقه إلى تعريف المحرر الإلكتروني بأنه الوسيلة الإلكترونية أو ما في حكمها عند إنشاء هذه الرسالة أو تخزينها أو إرسالها أو

وعرفها البعض " المحرر الذي يتضمن بيانات معالجاة إلكترونياً ومكتوبة وموقع عليه بطريقة إلكترونية وموضوع على دعامة مادية، مع إمكانية

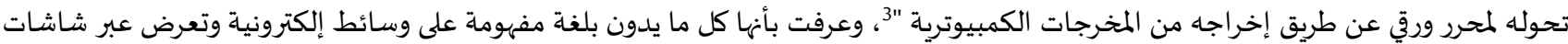
الإتصال المتعددة.4. وعرفها جانب آخر من الفقه بأنها " رسالة البيانات التي يتبادلها طرفا العلاقة التعاقدية ويمكن أن تكون الدليل الوحيد في إثبات التصرف القانوني الذي تم إبرامه إلكترونيا5. وعرفت بأها " مجموعة من الحروف أو الأرقام أو الرموز أو الأصوات أو أية علامات أخرى يمكن أن يثبت على دعامة إلكترونية تؤمن قراءاتها وتضمن عدم العبث بمحتواها وحفظ المعلومات الخاصة بمصدرها وتاريخ ومكان إرسالها وتسلمها والاحتفاظ بكافة المعلومات الأخرى على نحو يتيح الرجوع إليها عند الحاجةة. وذهبت الدكتورة نور العبد الرزاق إلى تعريف المحرر الإلكتروني بأنه كتابة توضع على وسائط إلكترونية بمعنى واضح ومزودة بتوقيع إلكتروني للتعرف على الشخص المنسوب إليه هذا التصرف 7.

$$
\text { الفرع الثاني: التعريف التشريعي للمحررات الإلكترونية }
$$
سنتناول تعريف الكتابة الإلكترونية من خلال تشريعات الدول المقارنة، ومن ثم سنعرفها في في التشريع الأردني.

أولاً: تعريف المحررات الإلكترونية في التشريعات المقارنة:

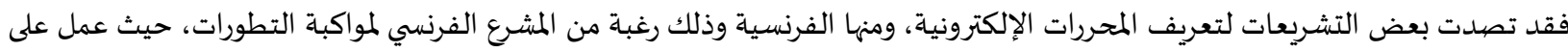

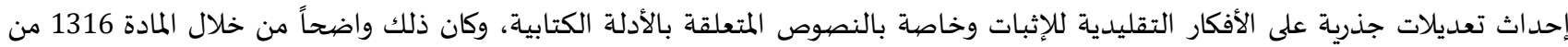

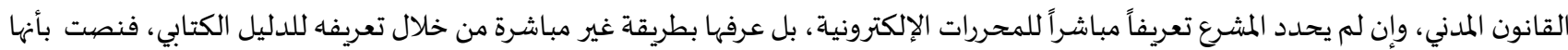

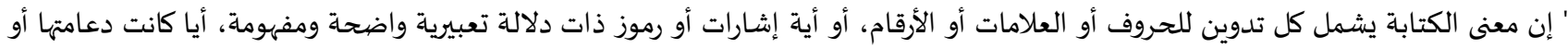
الوسيط الذي تنتقل عبره" ومما سبق يتضح لنا من النص السابق بأن المشرع الفرنسي قد أخذ بالتعريف الواسع للأدلة الكتابية دون الفصل بين مفهوم الكتابة والوسيلة

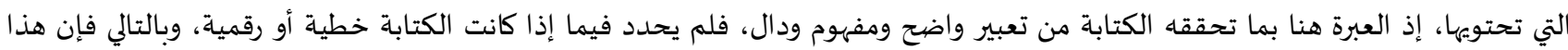

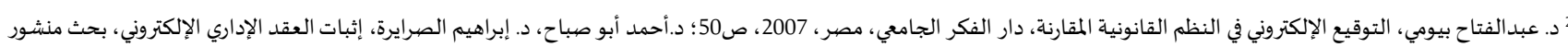

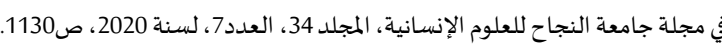

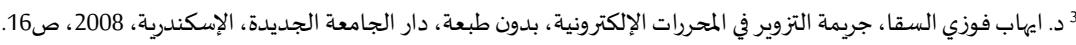

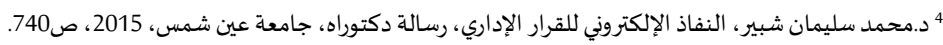

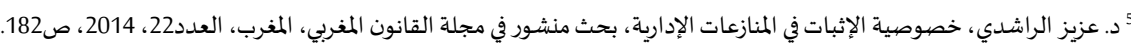

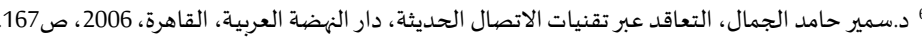

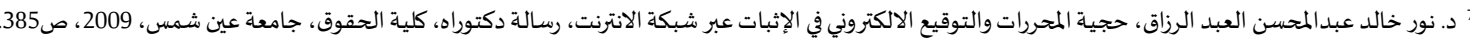
8 L'article 1316 du code civil Français no 2000 - 230 du 13 mars 2000 “ La prevue littérale ou prevue par écrit, Résulte d'une signification intelligible, quell que soient leur support et leur modéles de transmission “. www.legifrance.gouv.fr a la date: 28 - 10 - 2020 . 
التعريف الحديث للدليل الكتابي يتضمن بالطبع الدليل الإلكترونيف، ومن ذلك فقد تبنى المشرع الفرنسي مبدأ الحياد التقني والذي يقضي بعدم التمييز

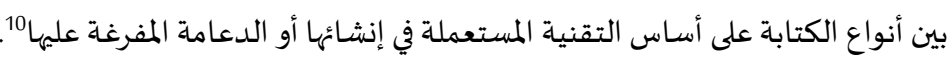
وإذ كانت بعض التشريعات قد احجمت عن الإفصاح عند وضع التعريفات عن إطلاق لفظ الكتابة وتركت هذا الأمر للفقه والقضاء، فإن المشرع

المصري أخذ السبق وقد حسم ذلك في التعاريف وذهب البعض إلى تأييد ذلكئ11، فنفرد عن غيره من التشريعات العبية الأخرى في تعريفه للكتابة

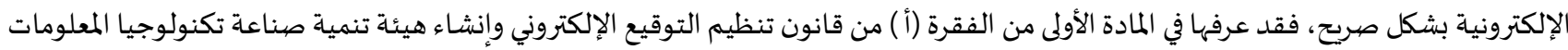

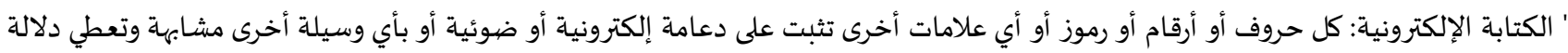

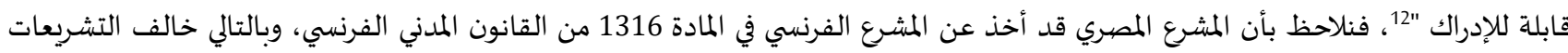

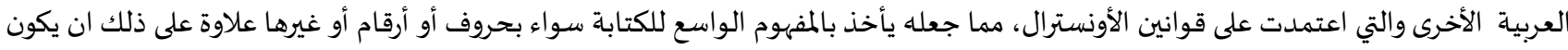

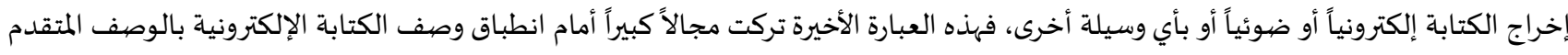

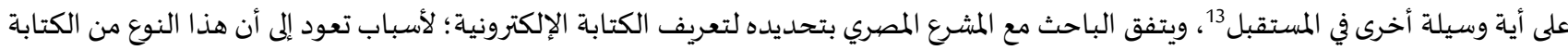

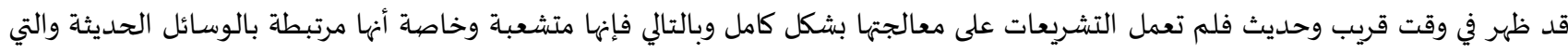

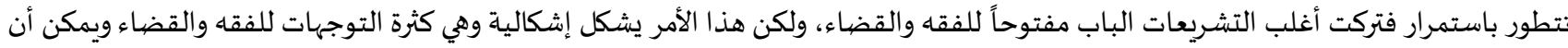
يحصل تضارب بين الأحكام في قضاء واحد .

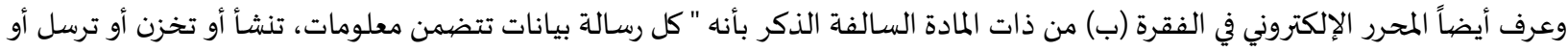

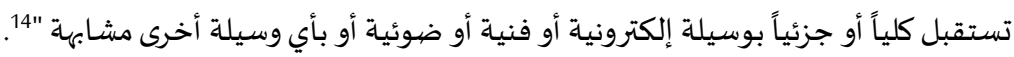

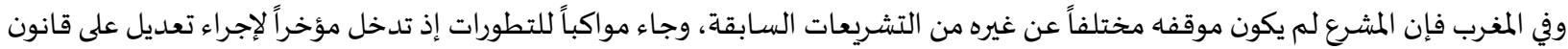

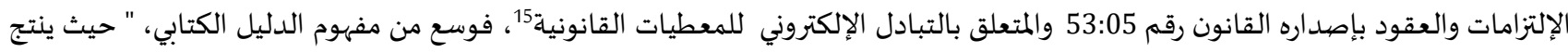

من ورقة رسمية أو عرفية ويمكن أن ينتج كذلك ... أو عن أي إشـارات أو رموز أخرى ذات دلات دلالة واضحةد، كيفما كانت دعامتها وطريقة إرسالها..."

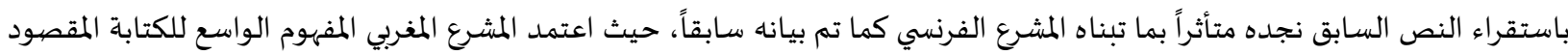

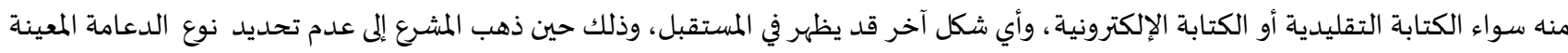

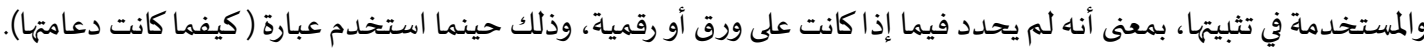

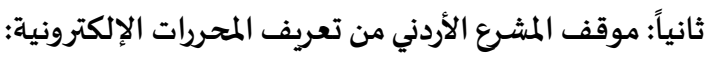

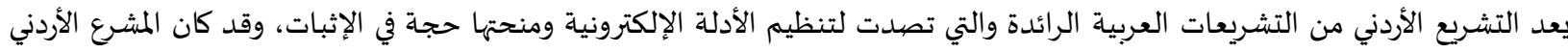
سباقا في تنظيم المعاملات الإلكترونية، فقد أصدر قانون المعاملات الإلكترونية المؤقت لسنة 2001 وعمل على تعديله (قانون رقم 15 لسنة السئ 2015)،

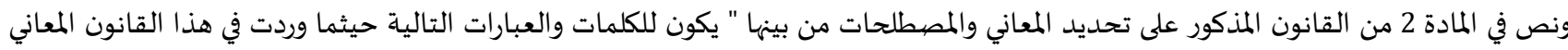
المخصصية لها أدناه ما لم تدل قرينة على غير ذلك الك..... رسالة المعلومات الإلكترونية: المعلومات التي يتم إنشاؤها أو إرسالها أو تسلمها أو تخزينها بأي وسيلة إلكترونية ومنها البريد الإلكتروني أو الرسائل القصيرة أو أي تبادل للمعلومات إلكترونياً. السجل الإلكتروني: رسالة المعلومات التي تحتوي على قيد أو عقد أو أي مستند أو وثيقة من نوع آخر يتم إنشاء أي منها أو تخزينها أو استخدامها

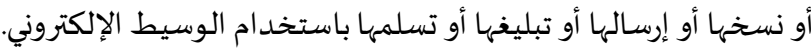
السند الإلكتروني: السند الذي يتم إنشاؤه والتوقيع عليه وتداوله إلكترونياً 17.

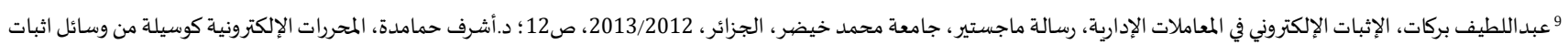

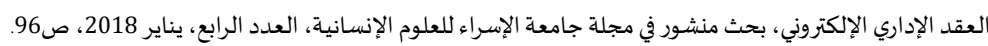

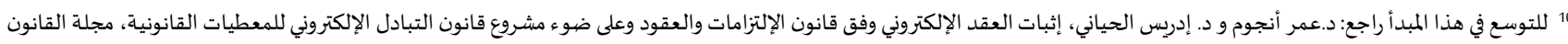

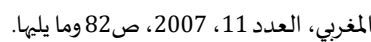
11 د.أحمد محمد أفندي، دور القاضي الإداري في الإثبات، رسالة دكتوراه، جامعة أسيوط، 2015 2015، ص350.

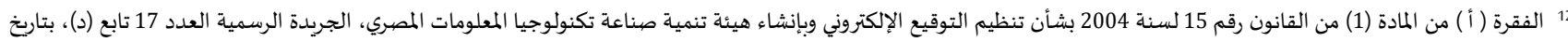

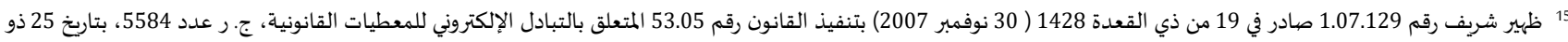

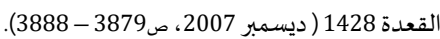

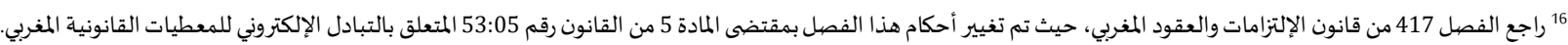

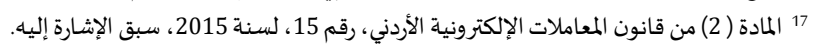


ومما سبق لاحظ الباحث بأن المشرع الأردني لم يعرف المحرر الإلكتروني بشكل مباشر، بل استعمل (السجل الإلكتروني، والسند الإلكتروني)

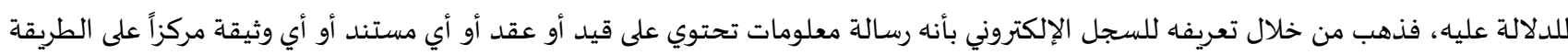

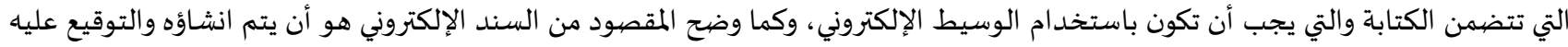

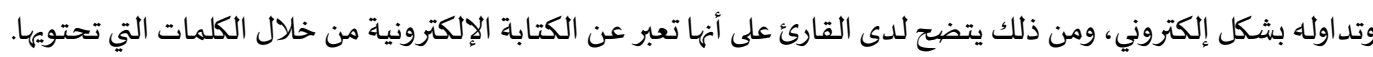

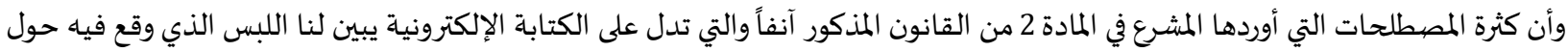

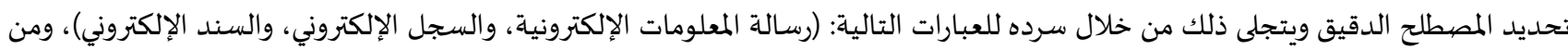

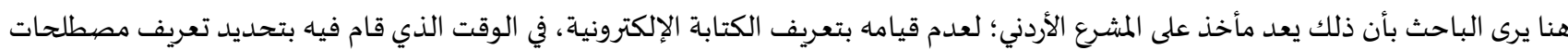
أخرى، نراها أقل أهمية منه.

\section{الفرع الثالث: تقييمنا لموقف الفقه والتشريع من مفهوم المحرر الإلكتروني}

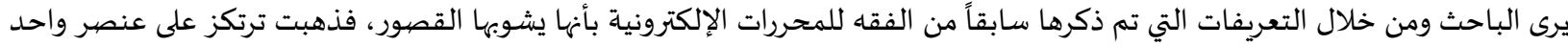

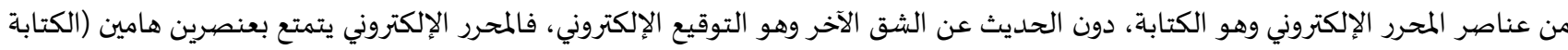

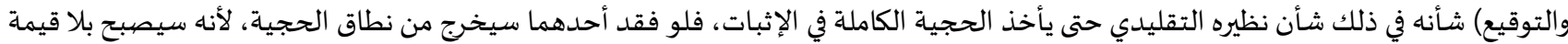

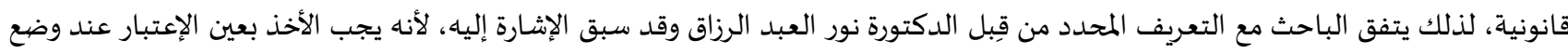
التعريف بوجود العنصرين السابق ذكرهما مع توافر شروطها.

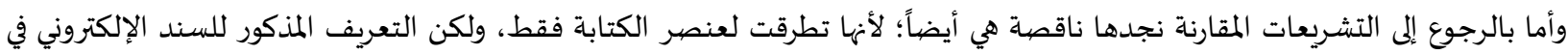

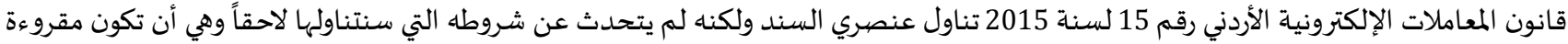
أو واضحةة، وأن يتم حفظها وغير قابلة للتعديل.

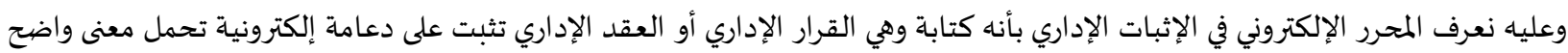

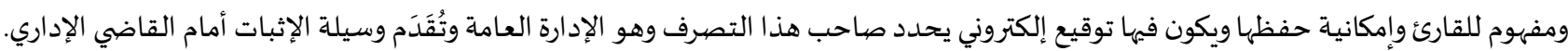

المطلب الثاني: شروط المحررات الإلكترونية: إلا أن الفقه اتفق على جملة من الشروط الواجب توافرها في المحررات الإلكترونية حتى يمكن الإعتداد بها لتحقيق وظيفتها في الإثبات، وهذه

الشروط هي:

أولاً: أن تكون الكتابة مقروءة وذات معنى واضح ومفهوم:

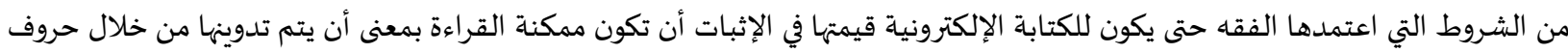

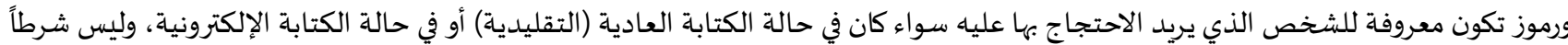

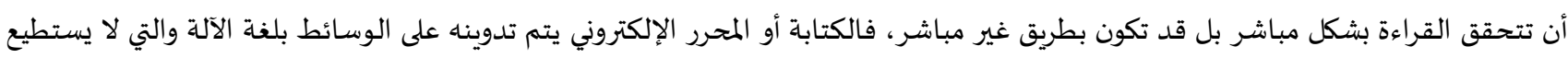

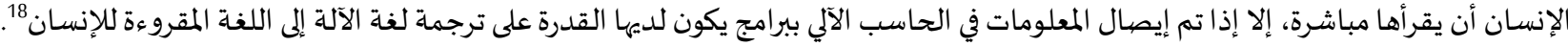

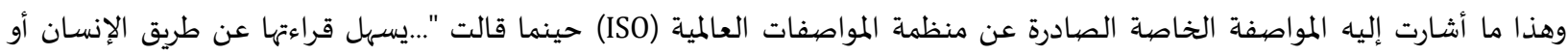

باستخدام آلة مخصصية لذلك"19 المارت

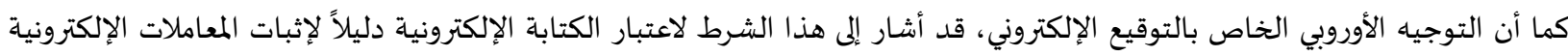

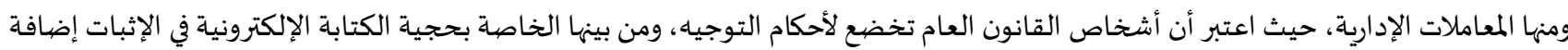

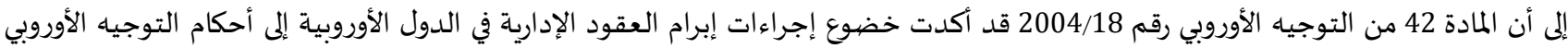

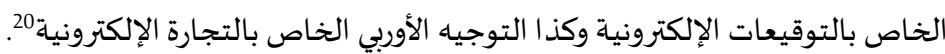

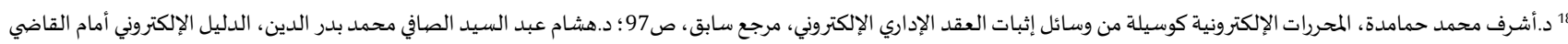

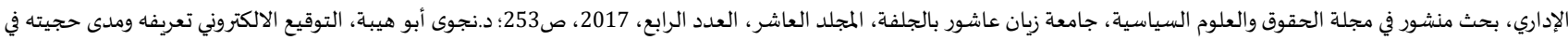

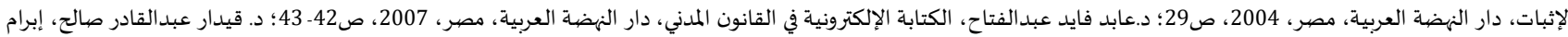

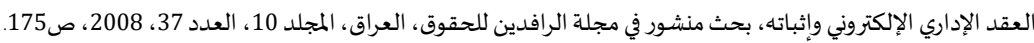

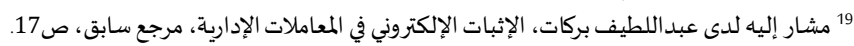

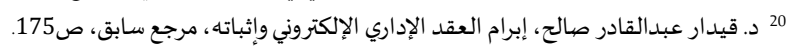


وقد ذهب مجلس الدولة الفرنسي إلى أن الكتابة أو المحررات الإلكترونية يجب أن تكون بشكل واضح ومفهوم للآخرين وخاصية القاضي حتى تكون الإنيا

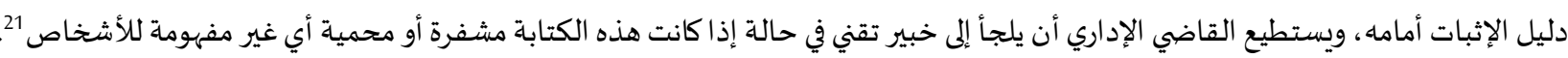

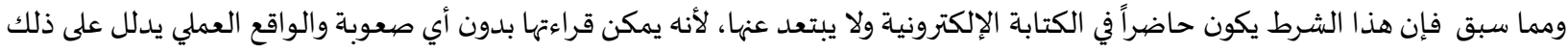

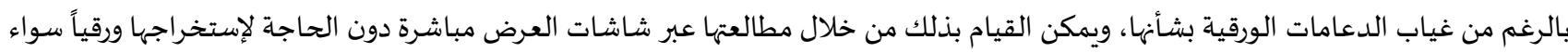

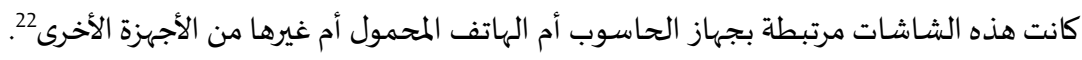
ثانياً: إمكانية الحفظ والاسترجاع: حتى يمكن للمحررات الإلكترونية أداء وظيفتها كدليل للإثبات، يجب أن يتم التدوين على وسيط يسمح بثبات الكتابة الكتابة عليه واستمرارها وعدم

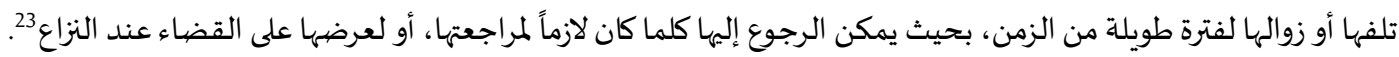

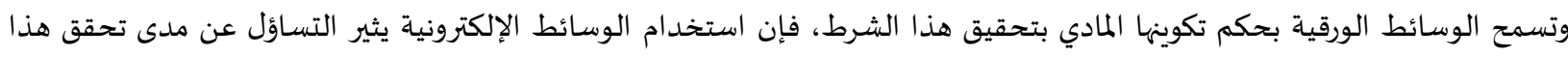

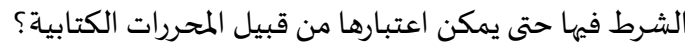

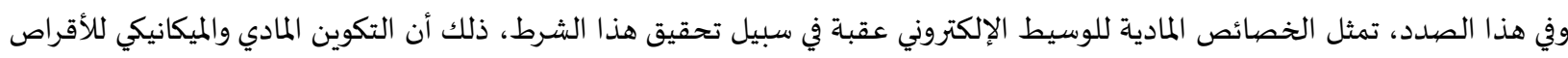

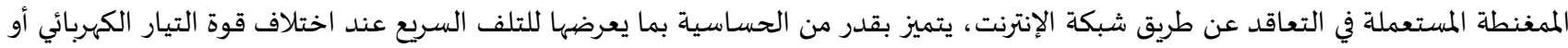

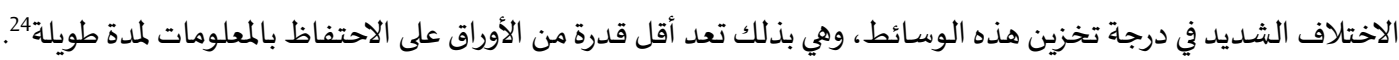

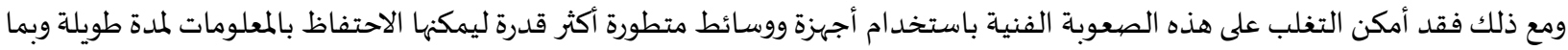

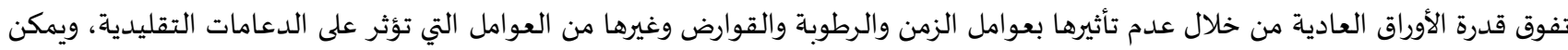

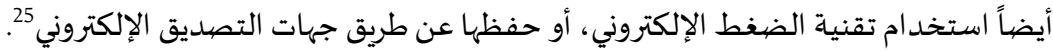

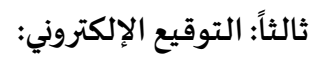

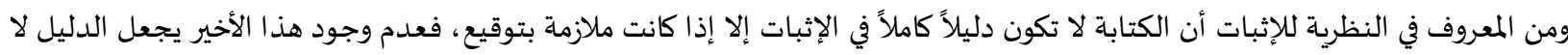

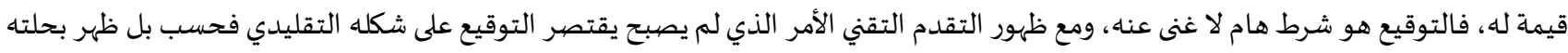

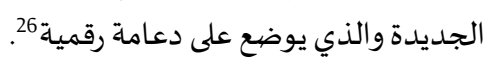

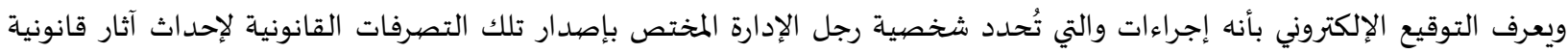

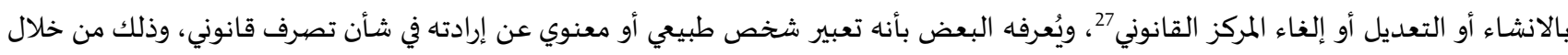

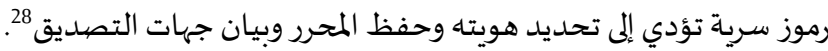

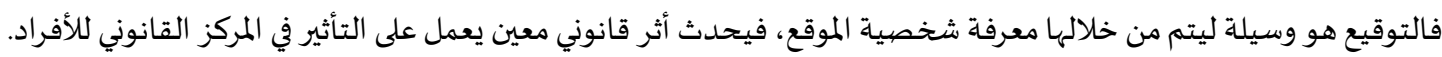
وبعد أن وضحنا مفهوم وشروط الكتابة الإلكترونية سنتناول حجيتها في الفقرة التالية.

$$
\text { المطلب الثالث: حجية المحررات الإلكترونية في الإثبات الإداري }
$$

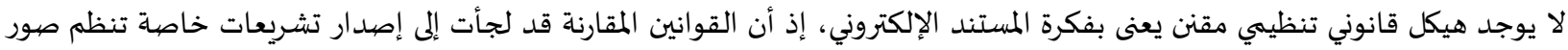

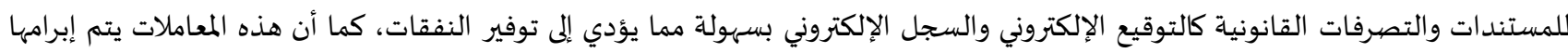
بوسيلة إلكترونية دون حاجة إلى وسيط.

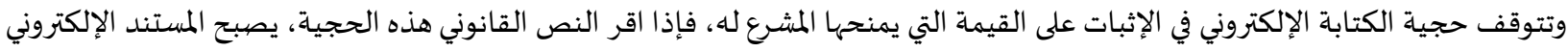

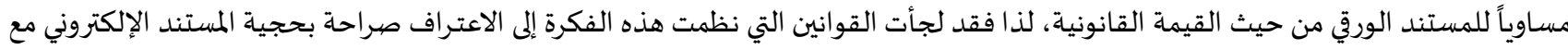
مساواته بالمستند الورقي 29.

${ }^{21}$ Eric CAPRIOLI, le juge et la preuve électronique, Contribution au colloque de Strasbourg « le commerce électronique : vers un nouveau droit » 8 - 9 octobre, 1999 , p. 4

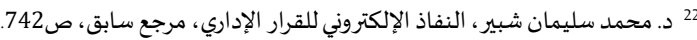

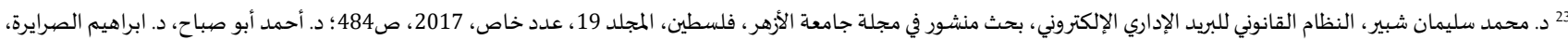

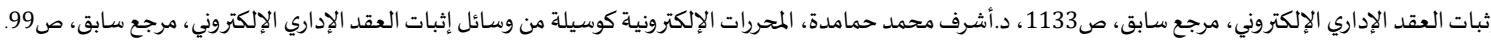

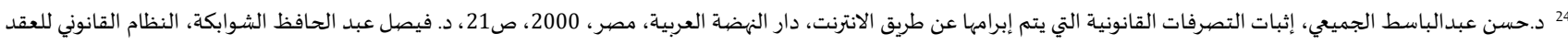

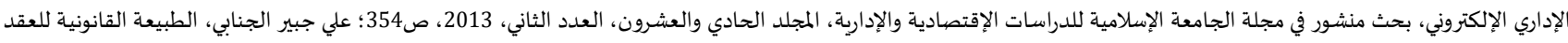

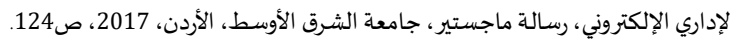

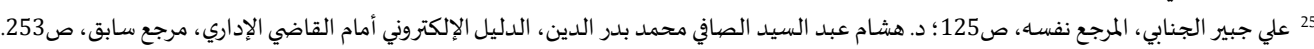

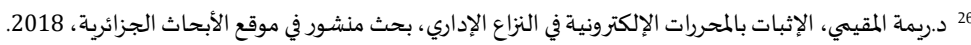

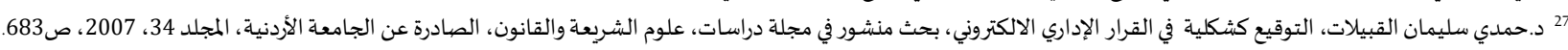

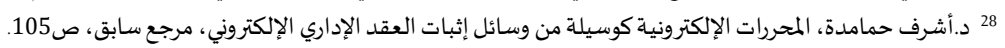


أولاً: موقف الفقه من حجية المحررات الإلكترونية في الإثبات الإداري:

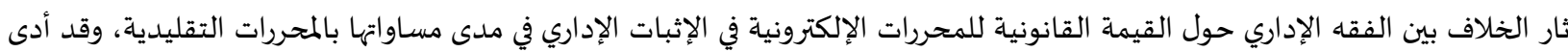
هذا الخلاف إلى رأيين مختلفين.

ذهب بعض الفقه الفرنسي بوجوب تدخل المشرع لتعديل قواعد الإثبات على نحو يسمح بأن يكون المحرر أو المستند الإلكتروني دليل كامل

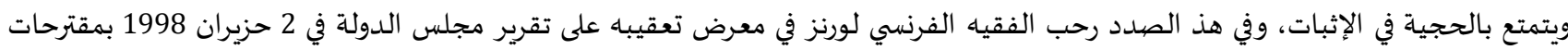

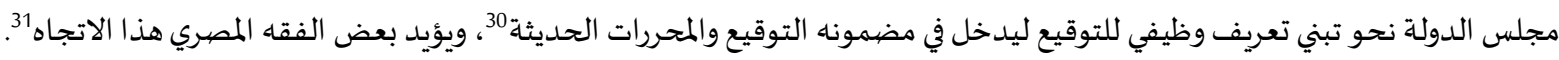

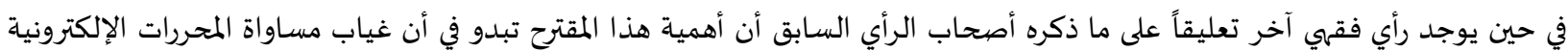

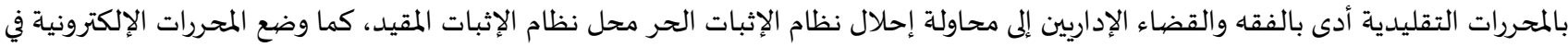

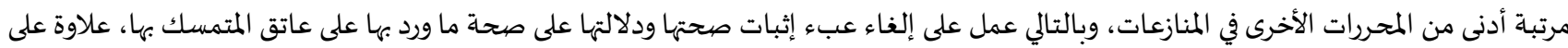

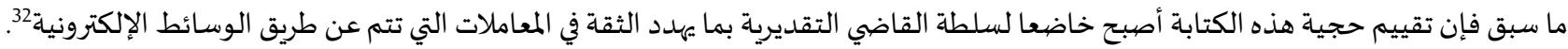

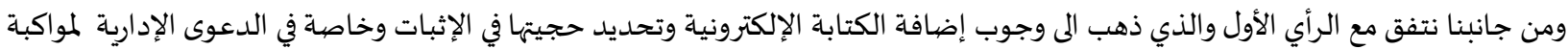

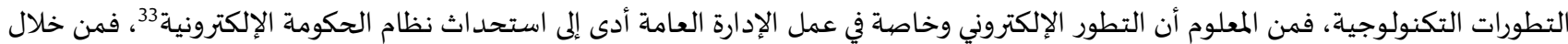
هذا الأخير باتت الإدارة تستخدم في تصرفاتها القانونية الإجراءات الإلكترونية الحديثة والتي أدت إلى ظهور القرار الإداري الإلكتروني.

ثانياً: موقف التشريعات من حجية المحررات الإلكترونية في الإثبات الإداري:

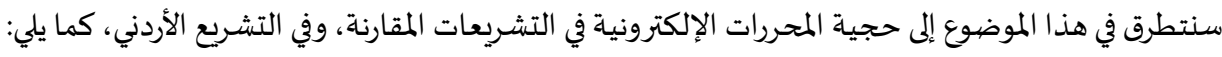
حجية المحررات الإلكترونية في الإثبات الإداري في التشريعات المقارنة جاء اعتراف المشرع بحجية الكتابة الإلكترونية في الإثبات في ظل وجود رغبة حقيقية لدياء بتبني معالجة التشريعات لكافة التحديات التي تثيرها

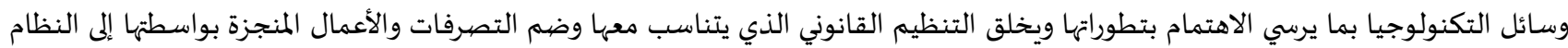
القانوني الحديث لمنحها الحجية والقوة القانونية للإثبات.

ولعل أهم ما أثير في هذا الأمر هو القيمة القانونية للأدلة المتولدة في نطاق الواتئ الواقع الإلكتروني ودورها في التدليل على وجود هذه الأعمال، وانطلاقاً من هذا الأساس بدأ المشرع في أغلب الدول بتنظيم كافة الأدلة التي يخلقها هذا الواقع ويجعلها في صلب الإهتمام التشريعي الراهن تحت مظلة المبادئ العامة في الإثبات التقليدي، بما يكشف عن سياسته الجديدة التي تقوم على التوازن بين الماضي والحاضر والمستقبل فئ في الإثبات وترجمة لذلك واستجابة من المشرع الفرنسي لمواكبة التطورات فقد عمل تعديل في القانون المدني والمتعلق بالإثبات، حيث أصببحت الكتابة

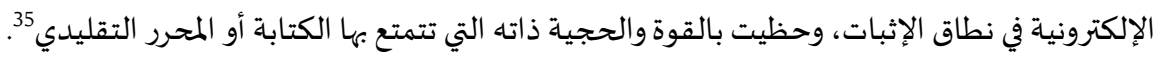

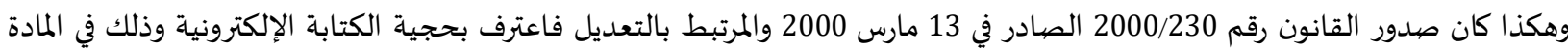
1366 من القانون المدني الفرنسي الجديد والمعدل سنة 2016 والذي نص على ما يلي " تتمتع الكتابة الإلكترونية بالحجية في الإثبات شأنها في ذلك شأن فأن الكتابة على دعامة ورقية بشرط أن تعد وتحفظ في ظروف من طبيعتها ضيمان سلامتها" ومن ذلك يتضح من خلال النص السابق أنه لم يضع المشرع الفرنسي أي درجات بين الدعامات الإلكترونية والورقية وإنما جعل المساواة كاملة

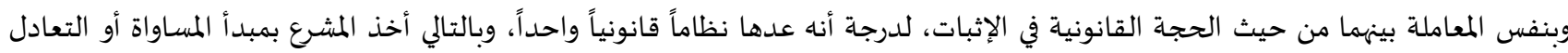
الوظيفي بين نوعي المستندات

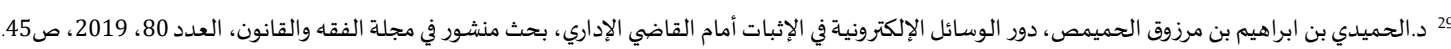

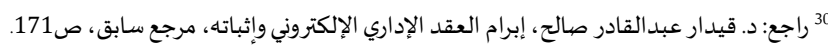

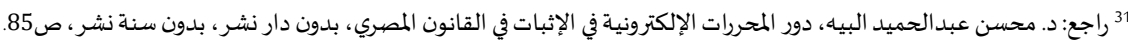

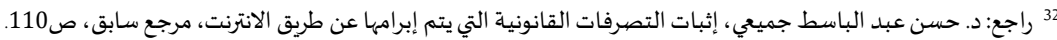

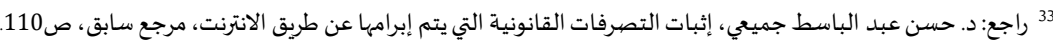

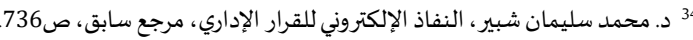

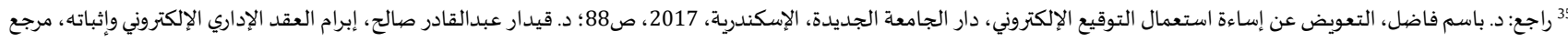

36 Art. 1366 du code civil ( Ord. no 2016 - 131 du 10 févr. 2016, art. 4, en vigueur le ler oct. 2016) « l'écnt électronique a la méme force probante que l'écrit sur support papier, sous réserve que puisse être dûment identifiée la personne dont il émane et qu'il soit établi et conservé dans des conditions de nature à en garantir l'intégrité ».

37 للتفصيل أكثر بشأن مبدأ التعادل الوظيفي بين المستندات الالكترونية والورقية أنظر: منية نشناش، مبدأ التعادل الوظيفي بين الكتابة الالكترونية والكتابة التقليدية في الاثبات، بحث منشور في

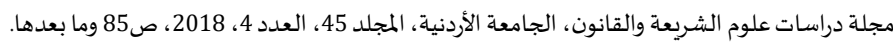


وكما ساير المشرع المصري نظيره الفرنسي، حيث عمل على مساواة الكتابة الإلكترونية بالكتابة التقليدية ونص بشكل صريح على هذه الحجية

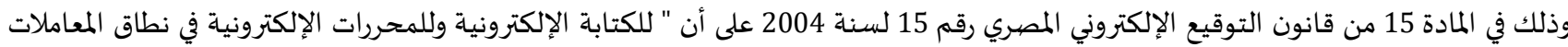

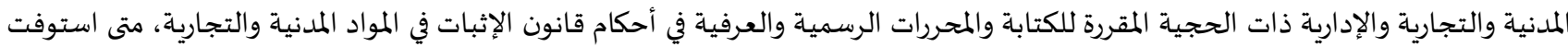

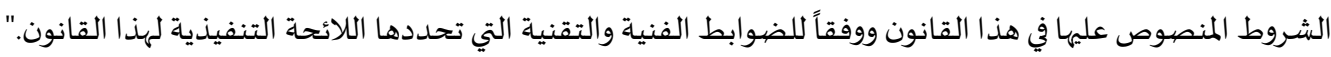
ونص في المادة 16 من ذات القانون السابق ذكره على تمتع التوقيع الإلكتروني والكتابة الإلكترونية بالحجية في الإثبات، في حال توافرت فيها ارتباط التوقيع الإلكتروني بالموقع وحده، وإمكانية كشف أي تعديل أو تبديل في بيانات المحرر الإلكتروني. وباستقراء النصين السابقين، يعترف المشرع المصري بحجية الإثبات بالكتابة الإلكترونية سواء كانت وسمية الموفية أو عرفية، وهو مسلك محمود من المشرع ونؤيده. وفي التشريع المغربي فقد تصدى هو أيضاً لموضوع حجبية الكتابة الإلكترونية وذلك حينما أشـار المشرع في مقتضيات قانون الإلتزامات والعقود في الباب المتعلق بالإثبات، واعترف بالمحرر الإلكتروني وبناء على التعديل فقد منح هذه المحررات ذات القوة الإثباتية التي تتمتع بها المحررات الورقية، وذلك

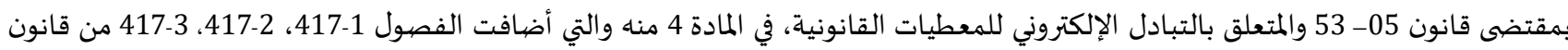
الإلتزامات والعقود المفربي 38.

فنص الفصل 1-417 والذي جاء في فقرته الأولى بأنه: " تتمتع الوثيقة المحررة على دعامة إلكترونية بنفس قوة الإثبات التي تتمتع بها الوثيقة المحررة على الورق.

وتقبل الوثيقة المحررة بشكل إلكتروني للإثبات، شأنها في ذلك شأن الوثيقة المحررة على الورق، شريطة أن يكون بالإمكان التعرف بصفة قانونية

على الشخص الذي صدرته عنه وأن تكون معدة ومحفوظة وفق شروط من شأها ضمان إنمان تماميتها" . • • حجية المحررات الإلكترونية في الإثبات الإداري في التشريع الأردني

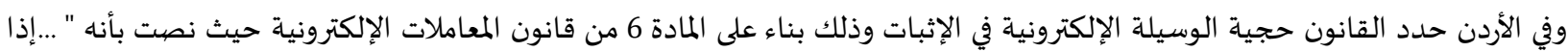
استوجب أي تشريع تقديم أي قيد أو عقد أو مستند أو وثيقة بشكل خطي أو كتابي فيعتبر تقديم السجل الإلكتروني الخاص بأي منها منتجاً للآثار

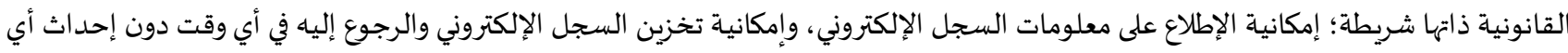
تغيير علياه." وكما ذهب المشرع أيضاً في المادة 7/ أ من ذات القانون بأنه " إذا اشترط أي تشريع تقديم النسخة الأصلية من أي قيد أو عقد أو مستند أو وثيقة

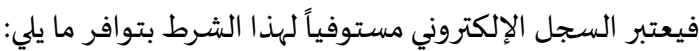

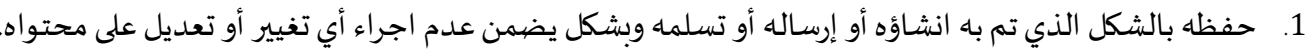

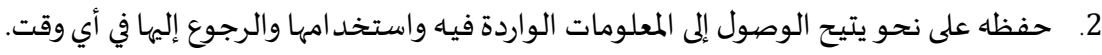

3. التمكن من التعرف على المنشئ والمرسل إليه وتاريخ ووقت انشائه أو أرساله أو تسلمهاء".

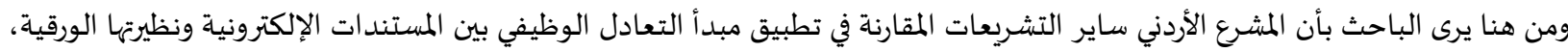
ويأخذ القضاء الإداري بتلك النصوص التشريعية السـابقة الذكر لتطبيق هذا المبدأ، وكما نرى بأن الشروط التي تم تحديدها من قبل التشريعات من

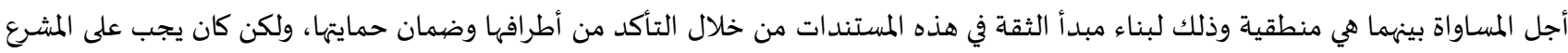

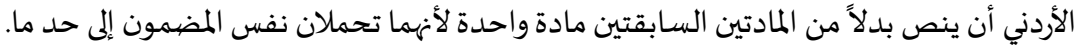

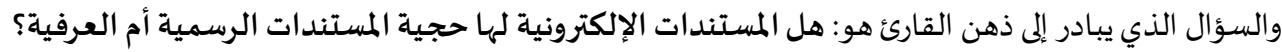

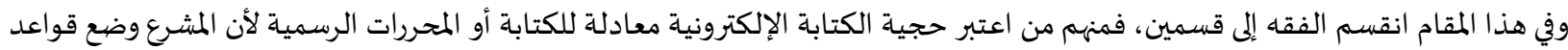

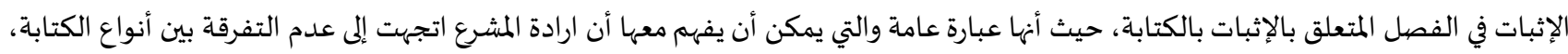

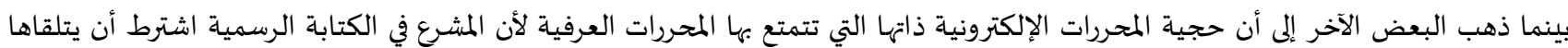

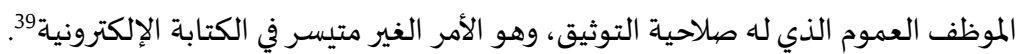

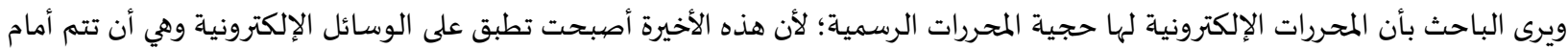
الموظف العام، وخاصية بعد ظهور مصطلح التوثيق الإلكتروني والموظف الإلكتروني.

38 حيث نصت المادة 4 من قانون التبادل الإلكتروني للمعطيات القانونية المفربي بأنه " يتمم الفرع الثاني من الباب الأول من القسم السابع من الكتاب الأول من الظهير الشريف المعتبر بمثابة قانون الالتزامات والعقود بالفصول

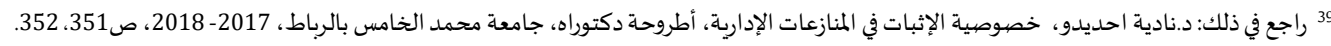


وكما رأينا سابقاً فإن المشرع المصري قد جعل المستندات الإلكترونية توازي المستندات الورقية الرسمية والعادية، أما المشرع الأردني فقد حدد

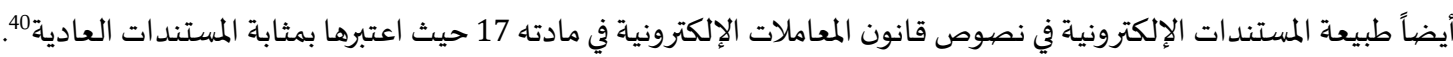
وكما رأينا سابقاً بأنه يترتب على الاعتراف التشريعي بالكتابة الإلكترونية بأن يتمتع هذا الأخير بالحجية الكاملة في الإثبات، وهي أن لا تقل درجة عن حجية نظيره التقليدي.

ولكن من نتائج الإعتراف بالحجية القانونية للمحرر الإلكتروني ظهور نوع جديد من التنازع بين الأدلة الكتابية، ويتجلى ذلك بوضوح عندما يكون

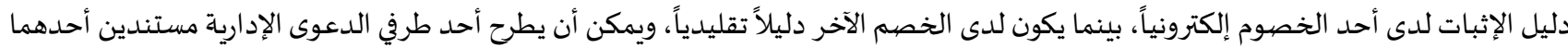

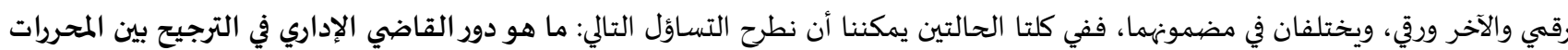

\section{الإلكترونية والورقية ولأي منهما تكون الأفضلية في الإثبات؟}

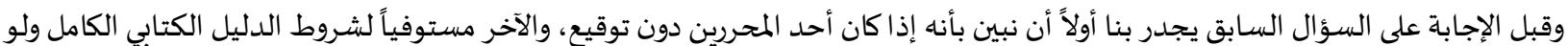

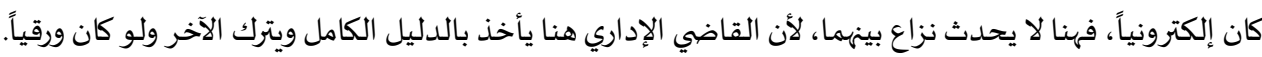

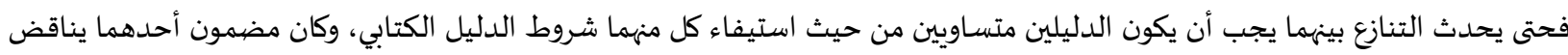
نظيره، وعلى القاضي أن يتأكد من ذلك ليرجح محرر على الآخر 41.

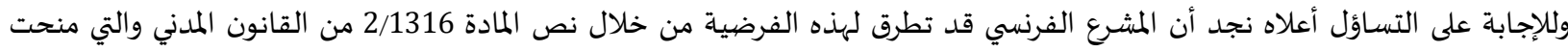

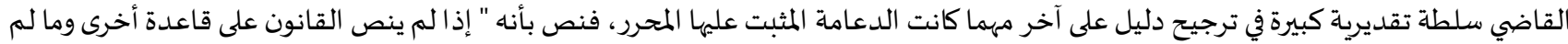

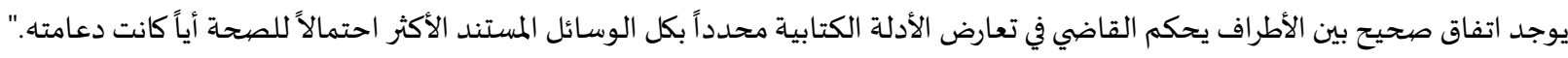

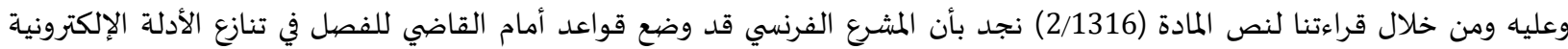

والورقية وهي:

1. الأخذ بعين الاعتبار فيما اذا كان هناك اتفاق بين أطراف الدعوى حول ترجيح دليل على آخر.

2. في حالة عدم وجود اتفاق، فيستعمل القاضي سلطته التقديرية لتحديد الدليل الأقرب للإحتمال والحقيقة وسواء أكان إلكتروني أو عادي.

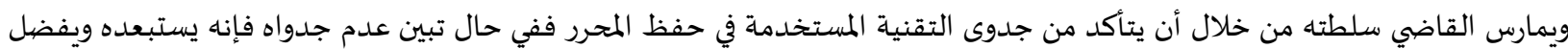

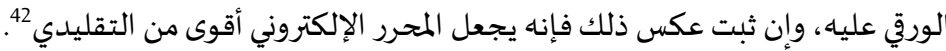

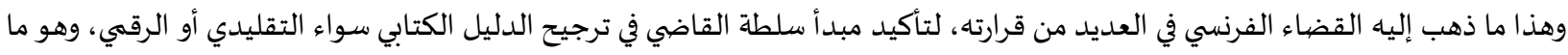
أدى إلى التعديل التشريعي ونرى بأنه يمكن الاستعانة بالنص السابق لمنح المحرر الإلكتروني حجية تفوق فيها المحررات التقليدية، وذلك عند تعارض ما يحتويه المحرر

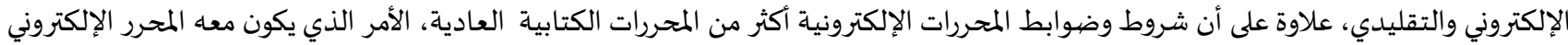
في مرتبة أعلى من غيرها من المحررات الأخرى ومن هذا المنطلق يمكننا القول بأن القاضي الإداري لا يمكنها من من حيث المبدأ أن يرفض وسيلة إثبات إلكترونية وأن يفضل عليه الإثبات الورقي انطلاقا من الطبيعة المادية المكونة لكلا الوسيلتين.

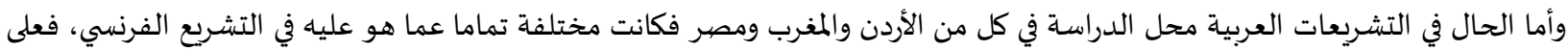
الرغم من وضع تشريعات تعالج موضوع الكتابة الإلكترونية إلا أها جاءت خالية من أية نصوص أو إشارة لحل هذه الإشكالية، وكما هو الحال في الواقع

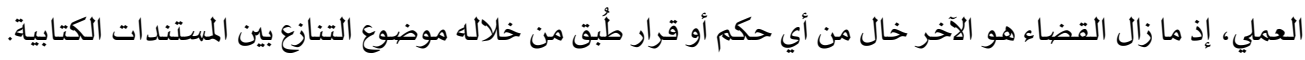

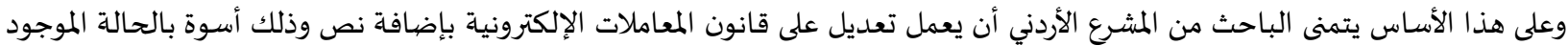

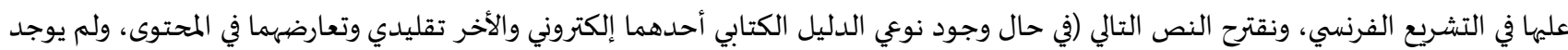
نص تشريعي ولا إتفاق بين الأطراف، فيحكم القاضيي بهذه المسألة بترجيح الدليل الذي يكون أقرب إحتمالاً للصحة مهما كانت دعامته المثبت عليها).

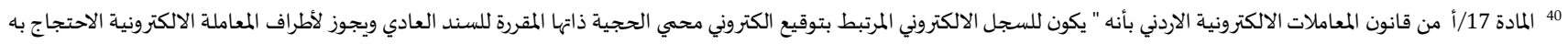

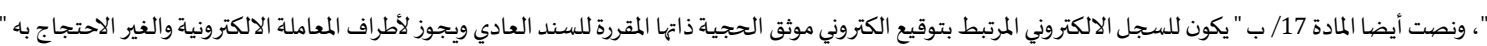

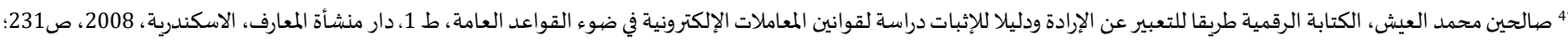

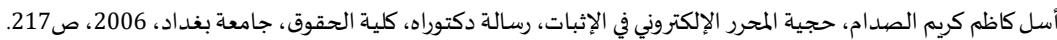

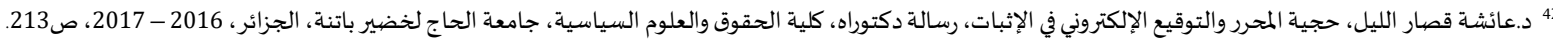
43 Giv 8 npv 1989, Bull. civ. I,n. 342 p. 230.

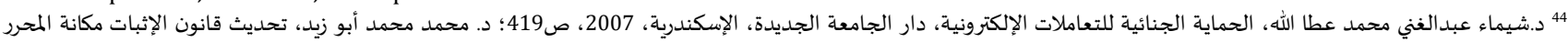

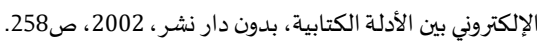


وذهب بعض الفقه إلى أن الاتفاق الذي نص عليه التشريع المدني الفرنسي في مادته 2/1316 منه، فأنه يتحقق في العقود الإدارية الإلكترونية، من

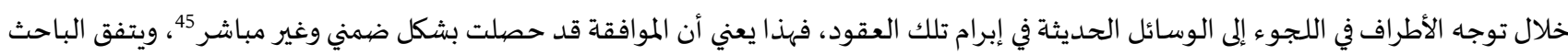

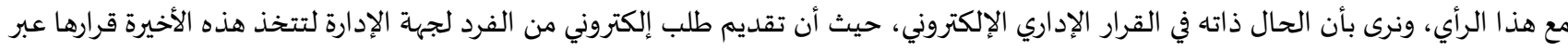

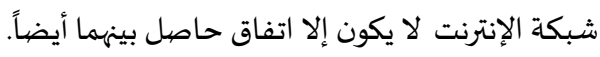

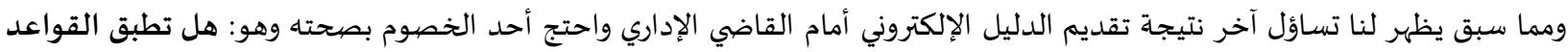

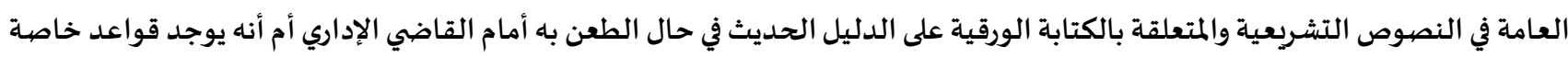

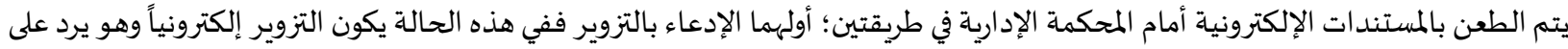

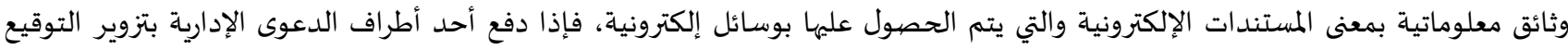

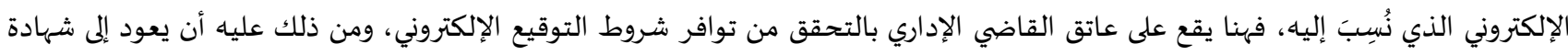

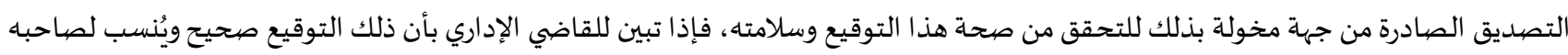

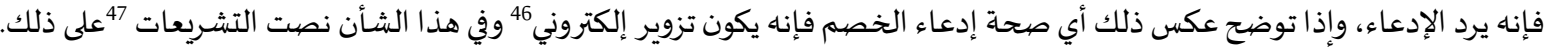

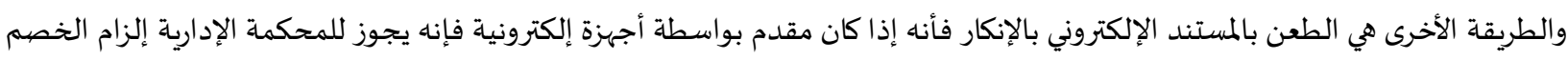

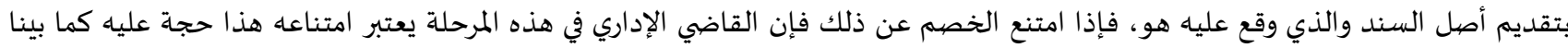

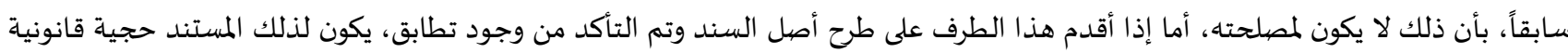

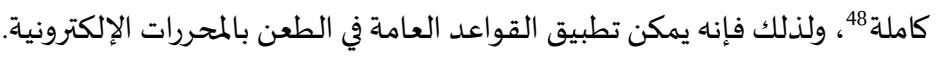

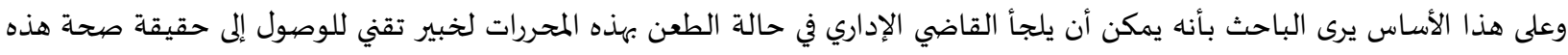

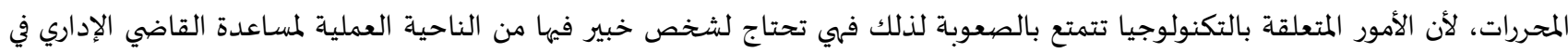
الدعوى المقدمة أمامه .

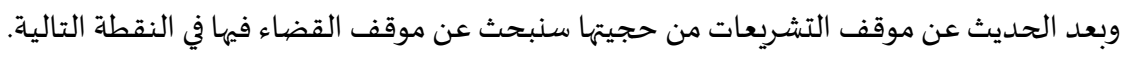
ثالثاً: موقف القضياء الإداري من حجية المحررات الإلكترونية في الإثبات:

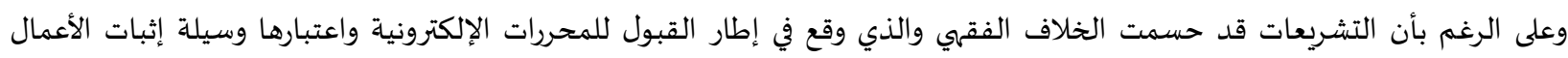

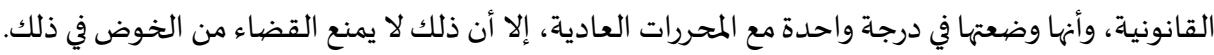

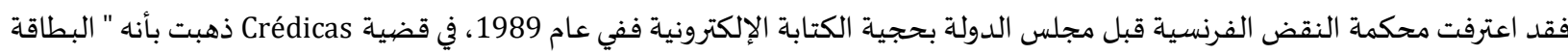

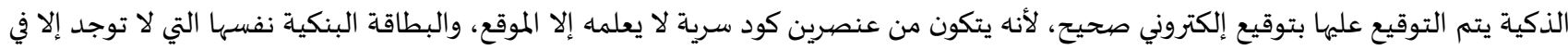

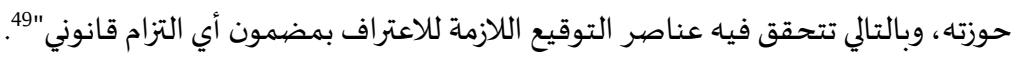

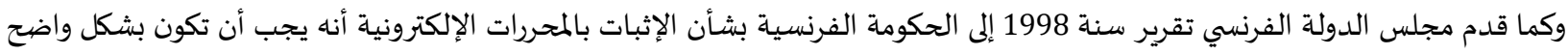

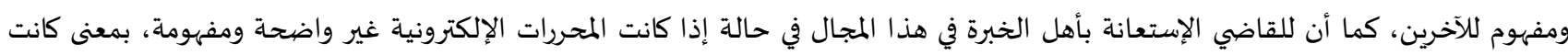

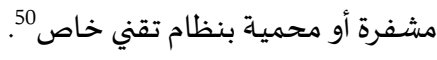

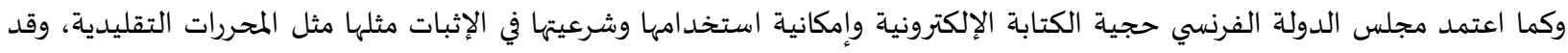

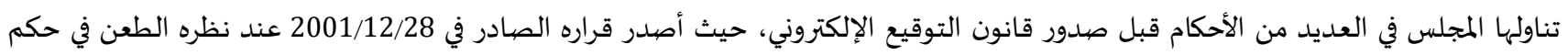

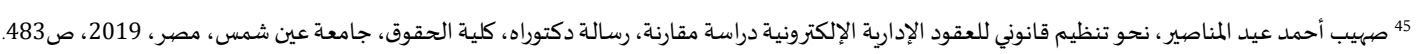

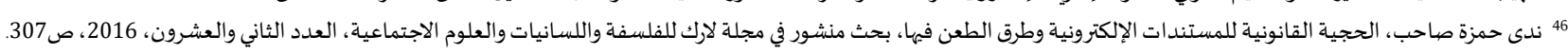

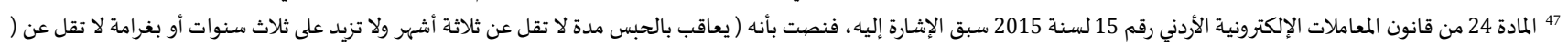

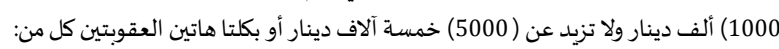

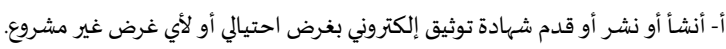

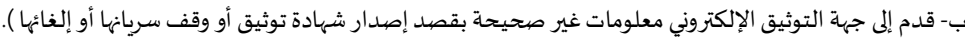

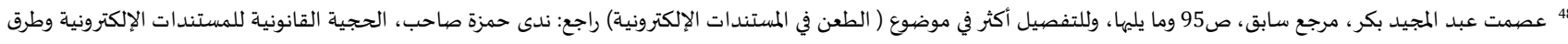
${ }^{49}$ Cass ; 1re ch. Civ. du 8 novembre 1989, Bull. Civ. 1, no 342. 
المحكمة الإدارية ل Nantes الصادر في 2001/6/7 51، و إن هذا القضاء يعتمد على ما نص عليه قانون العقود الإدارية الفرنسي رقم 2004/15 في مادته

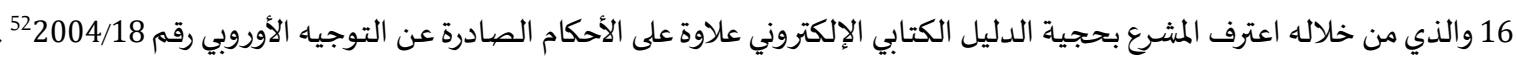
ولكل ما سبق ذكره نستطيع القول بأن ما يتمتع باه القاضي الإداري من سلطة تقديرية كبيرة في وسائل الإثبات فإن ذلك يقودنا إلى أن هذه إنهات

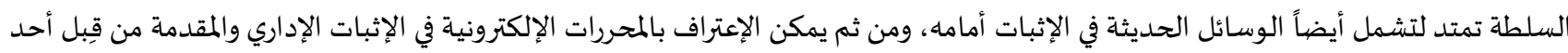

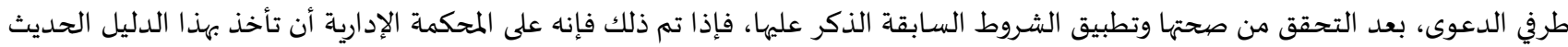

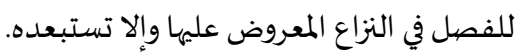
وسنتطرق بعد ذلك إلى وسائل الإثبات الإلكترونية الأخرى في المبحث المباء التالي.

\section{المبحث الثاني: المراسلات الإلكترونية كوسيلة الإثبات الحديثة أمام القضاء الإداري}

تقوم فكرة المراسلات الإلكترونية على تبادل الرسائل بشكل إلكتروني بين طرفين؛ المرسل (الإدارة) والمرسل إليه (الفرد) والتي ينتج عنها تصرف قانوني، ومن صهور هذه المراسلات؛ البريد الإلكتروني والفاكس والرسائل النصية القصيرة التصائ. وقد فرضت هذه الوسائل الحديثة نفسها في التعامل على نطاق واسع شمل كافة مجالات الحياة المختلفة، الأمر الذي جعل منهائ منها البديل العصري

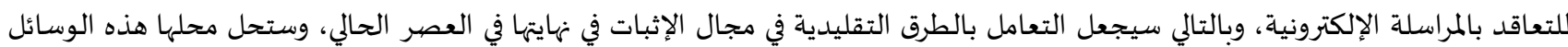

وللحديث أكثر عن هذا الموضوع فقد قسم الباحث هذا المطلب إلى مطلبين متواليين؛ في الأول البريد الإلكتروني، وفي الثاني الفاكس والرسائل

(sms).القصيرة)

المطلب الأول: البريد الإلكتروني كوسيلة الإثبات الحديثة أمام القاضي الإداري

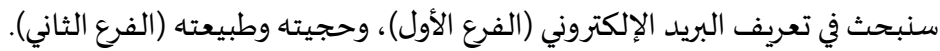

الفرع الأول: تعريف البريد الإلكتروني

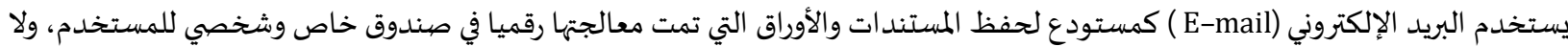

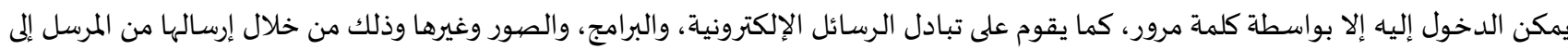

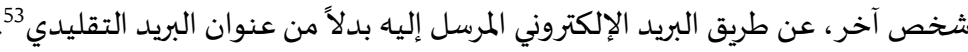

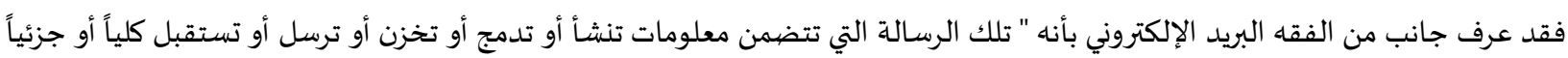
بوسيلة إلكترونية أو رقمية"54، وعرفه البعض بأنه " مجموعة الرسائل المتبادلة ذاتها أياً كان نوع نصوصهيا مكتوبة أو أغاني أو صور فيديو أو ملفات التهات

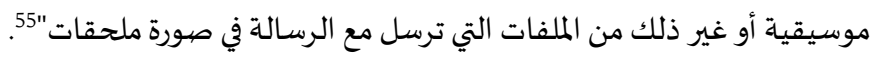
ويعرف بأنه عبارة عن خدمة تقدم لأي مستخدم لشبكة الإنترنت بطريقة مجانية بحيث يسمح للمشتركين ومن خلال العبات العلبة الإلكترونية بإرسال

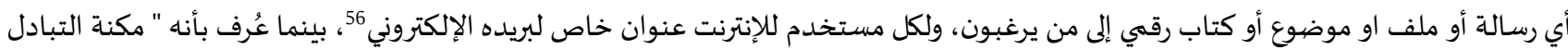

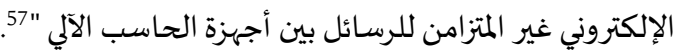

وعلى ضوء ذلك سعت الإدارة العامة في أغلب الدول في علاقتها مع الأفراد استخدام البريد الإلكتروني، فأصببحت تتواصل معهم وتمارس نشاطها

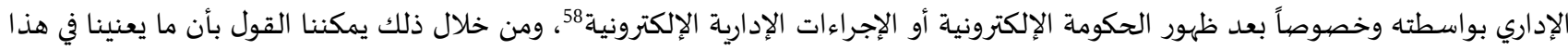
الشأن تعريف البريد الإلكتروني في الإثبات الإداري وهو الرسائل الإلكترونية التي يتم تبادلها بين المرسل والمرسل إليه (الإدارة والأفراد) وتتضهمن القرار الإداء

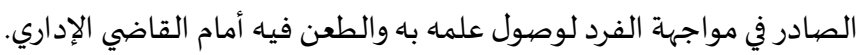

51 راجع في ذلك: د.أحمد محمد أفندي، دور القاضي الإداري في الإثبات، مرجع سابق، ص360.

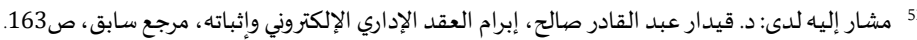

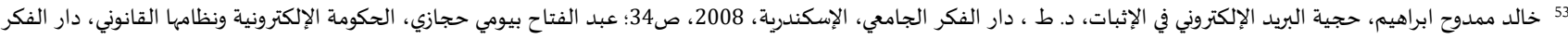

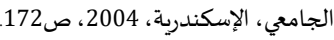
54 سارة فروجي، أدلة الإثبات الحديثة في المواد الإدارية، رسالة ماجستير، جامعاة محمد خيضر بسكرة، الجزائر،

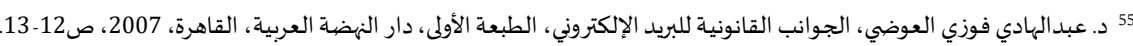

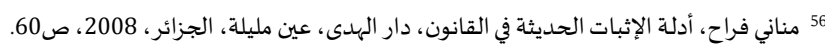

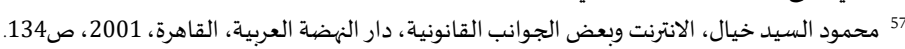

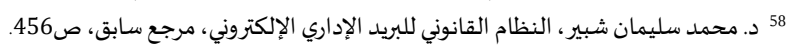


الفرع الثاني: حجية البريد الإلكتروني في الإثبات الإداري وطبيعته

يعتبر البريد الإلكتروني صورة من صور التقنيات الحديثة المستخرجة منها السندات الإلكترونية التي تمثل بيانات ثبوتية يقع خزها ونها ونقلها بشكل

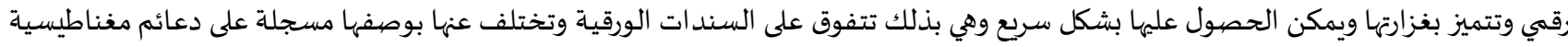

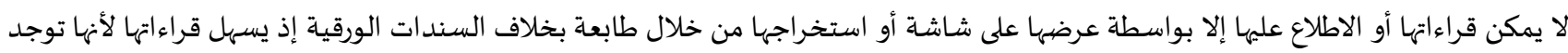
على شيء مادي ملموس 59 ويرجع السبب في ربط حجية البريد الإلكتروني بموقف القضاء إلى ما هو ثابت بشأن إعتبار القضاء الإداري لتنظيم مسائل الإثبات. سنتناول في هذه الفقرة حجية البريد الإلكتروني، وطبيعته القانونية. 1. حجية البريد الإلكتروني في الإثبات الإداري:

يثور سؤال في هذا المقام حول مدى قوة الرسائل المرسلة عبر البريد الإلكتروني في الإثبات الإداري؟ للجواب على هذا التساؤل لابد من توضيح أمرين:

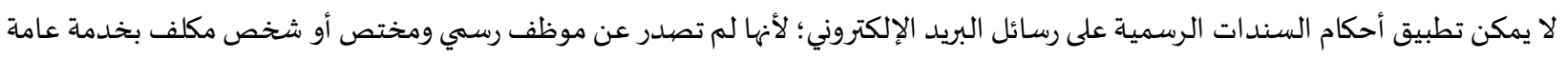

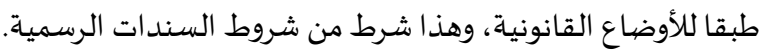
وبالتالي تعتبر لرسائل البريد الإلكتروني قوة الاسناد العادية (العرفية) في الإثبات ما لم يثبت موقعها أنها لم يرسلها ولم يكلف احد بإرسالها فعند ذلك تفقد هذه الرسائل قيمتها في الإثبات 60. وبالرجوع إلى قانون المعاملات الإلكترونية الأردني نجده أجاز اللجوء إلى الرسائل الإلكترونية بشكل عام، وعليها تنطبق هذه الأمور على رسائل

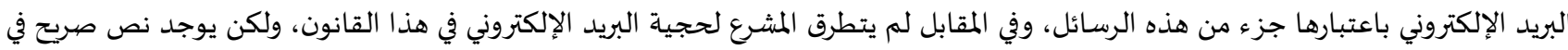

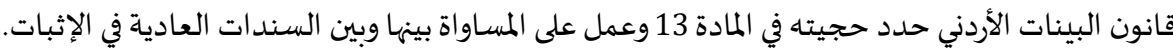
ومع ذلك يدعو الباحث المشرع الأردني لإصدار تشريع خاص لتنظيم وسائل الاثبات الإداري الإلكترونية، وحتى في حال وجود نص تشريعي خاص الماص

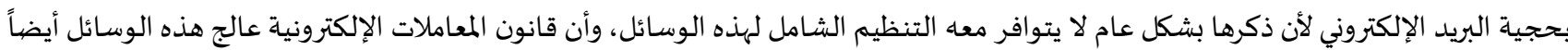
بصورة عامة. ومن زاوية أخرى سنسلط الضوء على أهمية دور القاضي الإداري في إرساء حجية البريد الإلكتروني انطلاقاً من سلطته الواسعة في مجال الإثبات

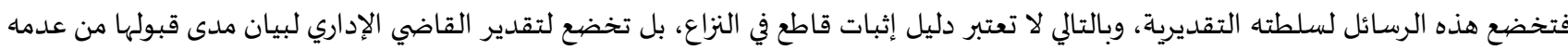

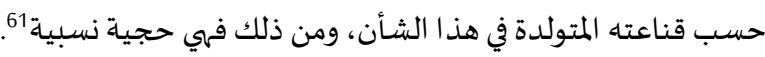

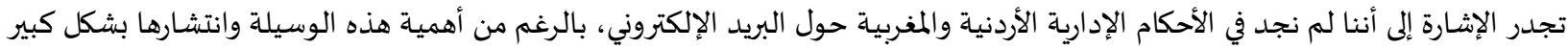
بين الأفراد وغير مستبعدة للإدارة. وعلى الرغم من ذلك فإن الدور الكبير والإيجابي الذي يلعباء القاضي الإداري يمكن أن يساهم إلى حد كبير في قبول القاضي لوسائل الإثبات

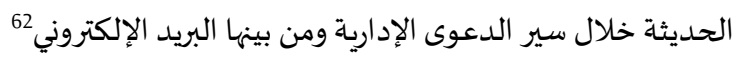

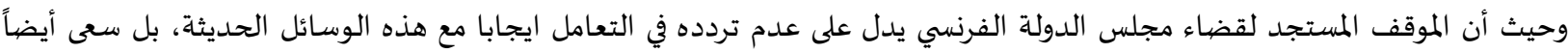

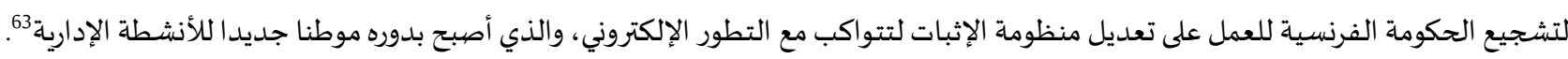

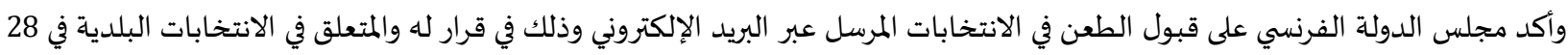
دجنبر 2001 لبلدية (entre- deux-monts بأنه "...وحيث أنه يستنتج من البيانات، ولا سيما الاعتراف الصادر عن المحافظة احتجاج السيد (M.G) ضيد العملية الانتخابية التي جرت في البلدة في 11 مارس 2001، وأكد السيد (M.G) وبعد أن يؤكد صاحب هذا الاعتراض برسالة موجهة إلى المحكمة

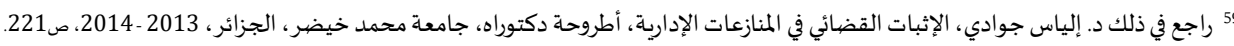

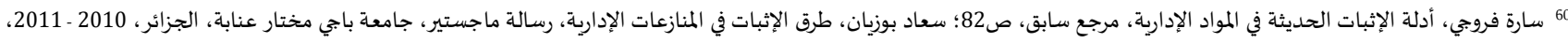

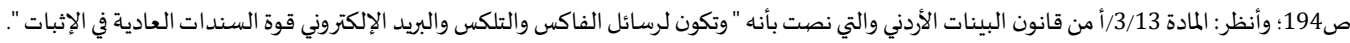

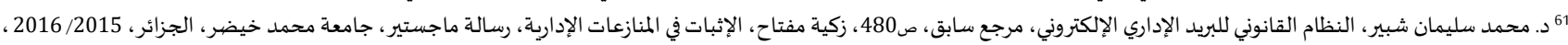


الإدارية (besançon) أن هذا الاحتجاج كان مقبولاً..."64)، وذهبت المحكمة الإدارية نانت باعترافها بصلاحيته في تسيير إجراءات التقاضي، وتقديم الطعن

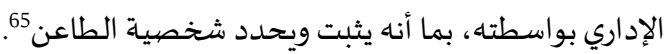
وفي نفس السياق أقرت محكمة الاستئناف في باريس بتاريخ 16 نوفمبر 2001 بصحة استقالة قدمت بواسطة البريد الإلكتروني واعتبرت أنه بمثابة

إعلان لإرادة واضحة من جانب المستقبل 66. ومما سبق يدعو الباحث القضاء الإداري الاردني للسير على خطى مجلس الدولة الفرنسي، والاهتداء بموقفه السابق.

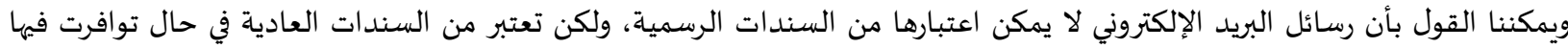

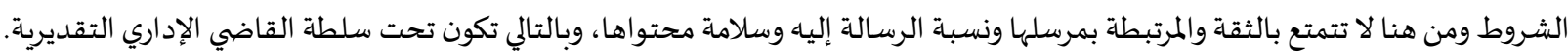

2. الطبيعة القانونية للبريد الإلكتروني:

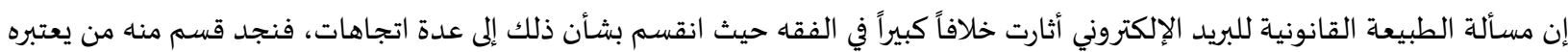
صورة جديدة للإسم الشخصي لأن الجزء الأول من هذا العنوان عادة ما يحتوي على اسم صاحب البريد ولقبه فيؤدي بالنهاية إلى تمييز الشخص عن عن

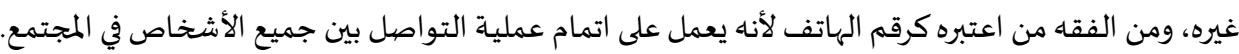

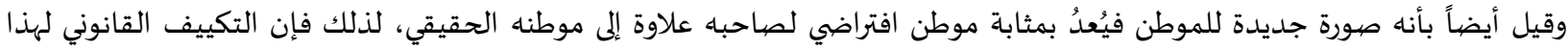

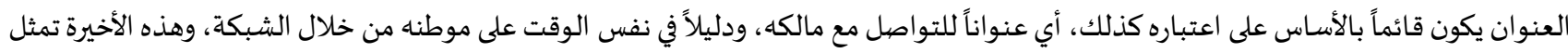

وظائف العنوان أو أهد افه، التي يساهم في وجودها أو تحققها ليس أكثر 67

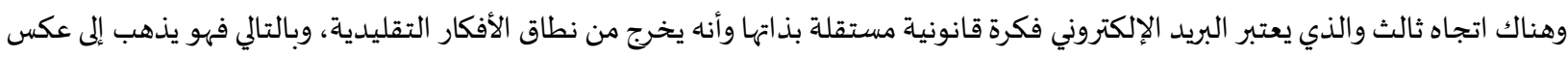

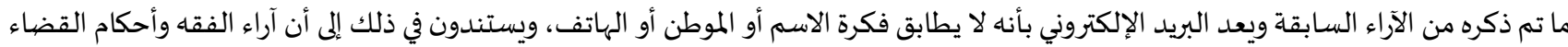

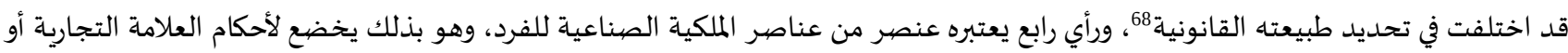

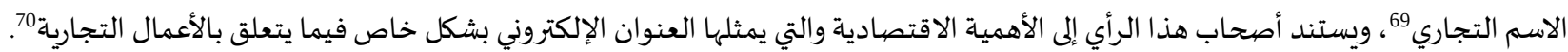

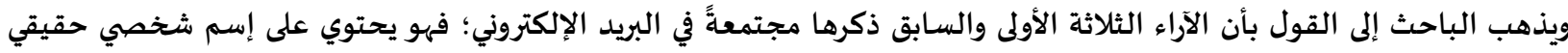

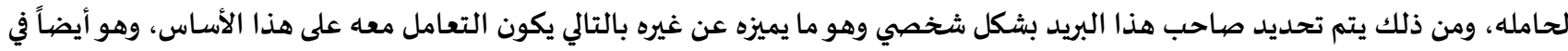
نفس الوقت يعد موطناً فهو يحدد موطن صاحب البريد من خلال ذكر رمزبلده بالتالي فهو موطن إفتراضي كما يؤدي البريد الإلكتروني إلى تمكين

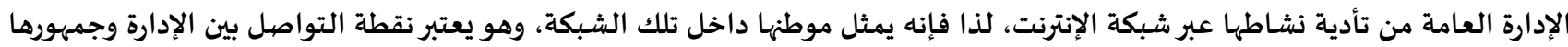

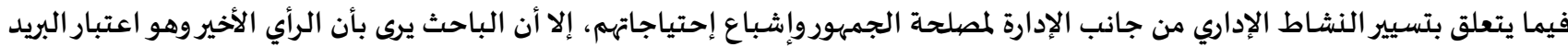
الإلكتروني من عناصر الملكية الصناعية فهو غير موفق؛ لأنه لا يتعلق بالعلامة التجارية فهو لا يعد نشاطاً أو الأومالاً تجارياً.

الفرع الثالث: الفاكس والرسائل القصيرة (SMS) في الإثبات الإداري

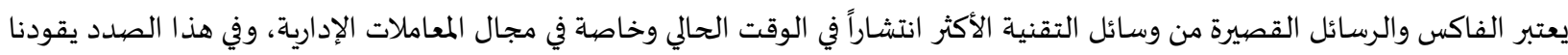
إلى التساؤل التالي: ما مدى حجية الأوراق المرسلة عبر الفاكس الرسائل القصيرة في الإثبات؟ وما هو دوسئ دور القاضي الإداري فهها؟

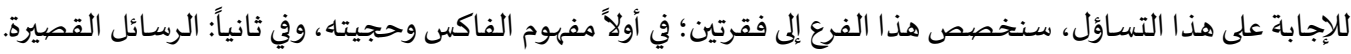
أولاً: مفهوم الفاكس وحجيته:

وعلى ذلك سيتم تقسيم هذا الموضيوع إلى تعريف الفاكس أولاً، وحجيته ثانياً.

1

يعرف بأنه جهاز الاستنساخ عن بُعد أو نقل الصورة عن بُعد 717، وكما يعرف بأنه جهاز يعمل عن طريق تقنية الاتصالات ويقوم بإرسال نسخ طبق

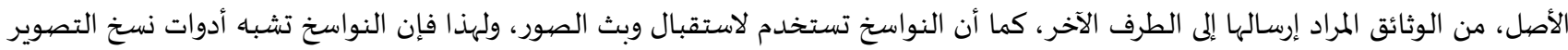

64 - C :E, 28 Décembre 2001, req. no 235784.

65 راجع بشكل مفصل فيما يتعلق بحكم المحكمة الإدارية Nanet الفرنسية؛ د. موسى شحادة، الإدارة الإلكترونية وإمكانية تطبيقها في رفع الدعوى أمام القضاء الإداري بالبريد الإلكتروني، بحث منشور

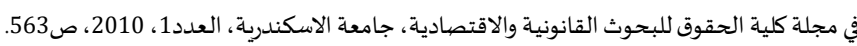

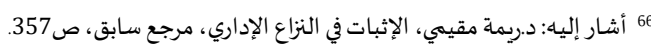

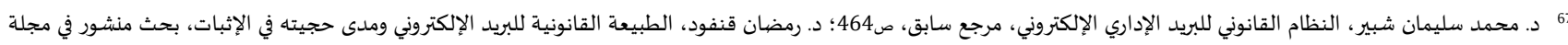

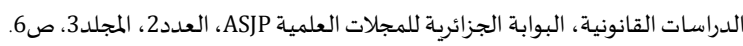

68 -Lamy, Droit de l» informatique et des réseaux, 2001, Division ll, L », no 2335, p.1318

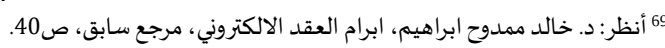

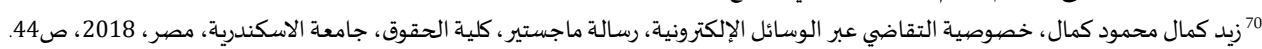

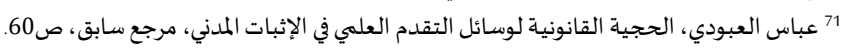


الصغيرة، إلا أهها تكون مزودة أو متصلة بالهاتف، حيث يمكن نقل الرسائل والمستندات المخطوطة باليد أو بالطباعة بكامل محتوياتها نقلاً مطابقاً

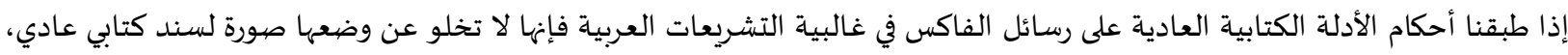
فأهملها بعض التشريعات العربية ولم تعطيها أية حجية معينة في الإثبات؛ ومن ذلك المشرع الجزائري، ولم تأخذ بالمفهوم الوارد في القانون المدني

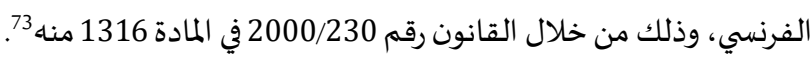
ولم ينظم المشرع المفربي هذه الوسيلة بشكل صريح، لكن نص في الفصل 1- 417 من قانون الالتزامات والعقود حيث عمل على مساواة المحرر

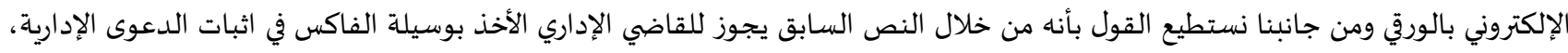
كونها تعد من الوسائل الإلكترونياة.

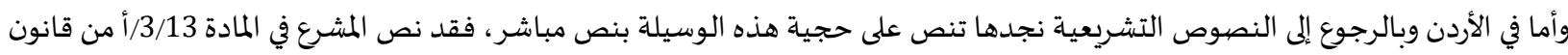

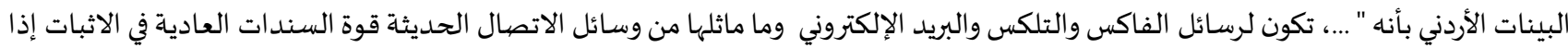

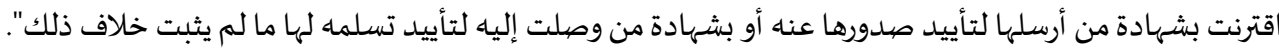
موقف القاضي الإداري في إثبات الدعوى الإدارية بواسطة رسائل الفاكس: اعترف القضياء الفرنسي بالرسائل التي يتم إرسالها عبر الفاكس، فنذكر حكم محكمة النقض الفردئسية في 15 ديسمبر 1992، فنازع أحد

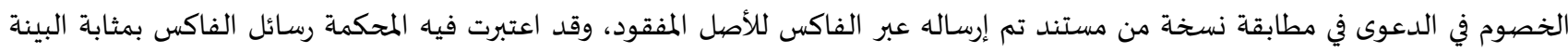
الخطية ومنحتها حجية الأوراق العرفية في الإثبات 74.

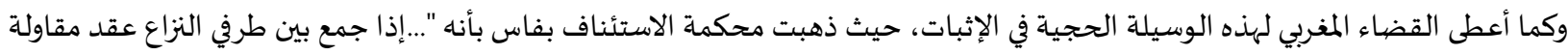

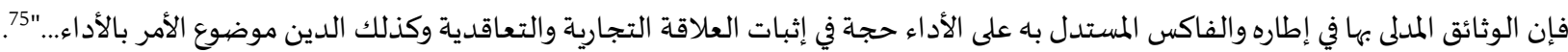

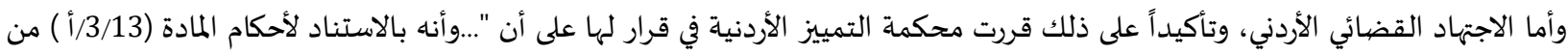

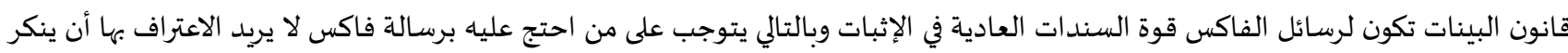
صراحة ما منسوب إليه من خط أو توقيع..." وأما بخصوص القضياء الإداري، فإننا لم نتمكن من تحديد موقف إنف واضح حول مكانة رسائل الفاكس في الإثبات الإداري، نظراً لقلة إن لم نقل

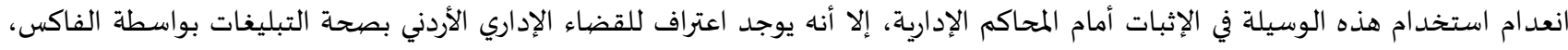

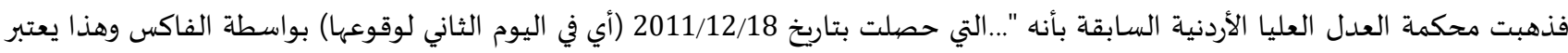
إشعاراً خطياً وليس شفوياً للإبلاغ عن الإصابة ومرفقاً به نموذج إصابة العمل وإخطار حادث العمل..."77.

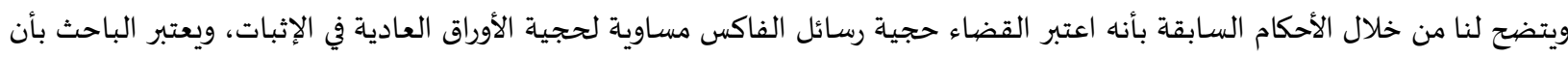

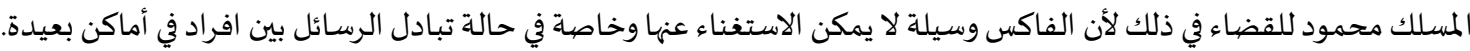

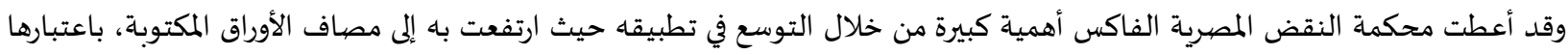

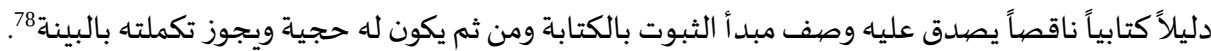

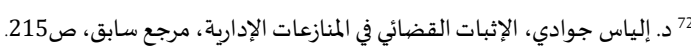

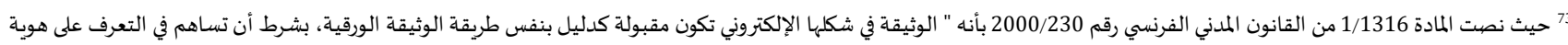

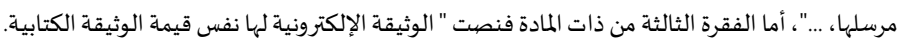

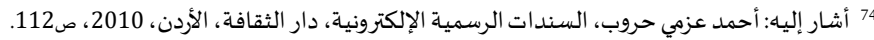

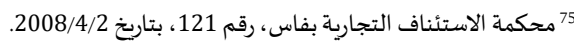

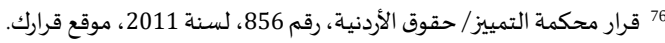

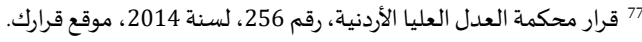

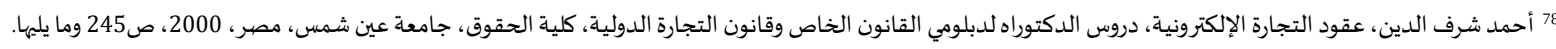

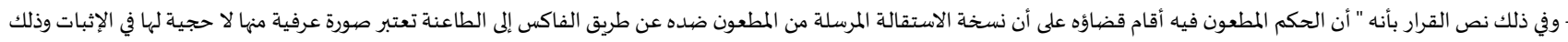

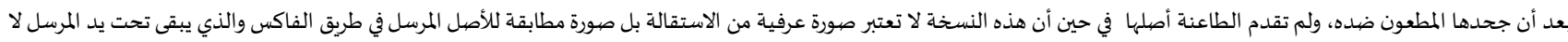

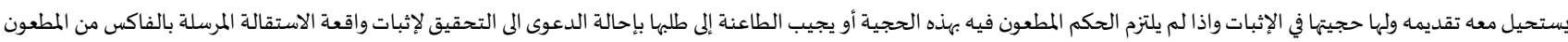

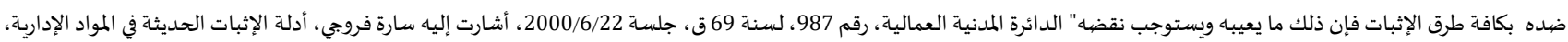


ومما سبق يرى الباحث بأن رسائل الفاكس تتمتع بكامل الحجية القانونية في الإثبات في حالات اذا اقترنت بشهادة من أرسلها أو من استقبلها

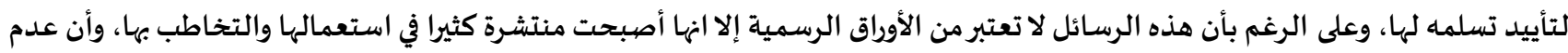

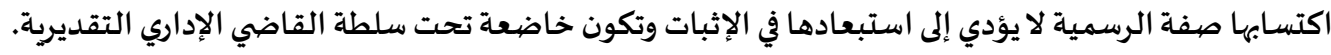

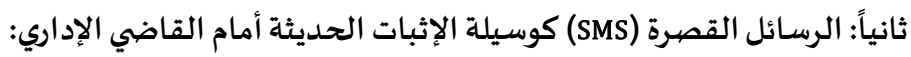

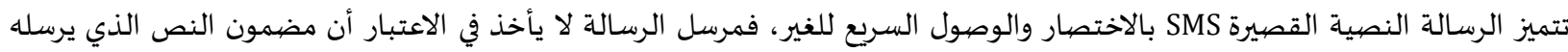
سيترك أثرا قابلا للإثبات، حيث إن المستند الورقي -بمعناه التقليدي - يمكن أن يتلف بسهولة على خلاف الرسالة النصية التي تبقى محفوظة على موقع وبرنامج التواصل لدى كل من المرسل والمرسل إليه، ويمكن استخراجها حتى ولو تم حذفها من ذاكرة الهاتف بواسطة خبراء مختصين في مجال الذاكرة الإلكترونية الداخلية للجوال. وعلاوة على ذلك فإنه في حالة إتلاف وسيلة التواصل نفسها، فإن ذلك لا يؤدي بالضرورة إلى اختفاء الرسائل النصية التي

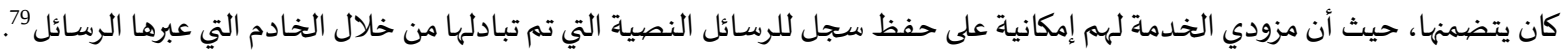

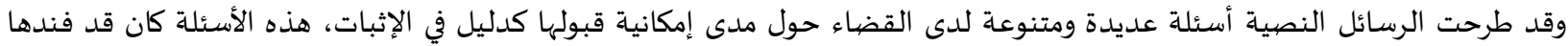

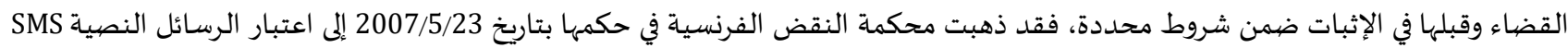

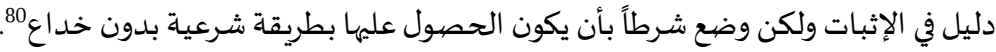

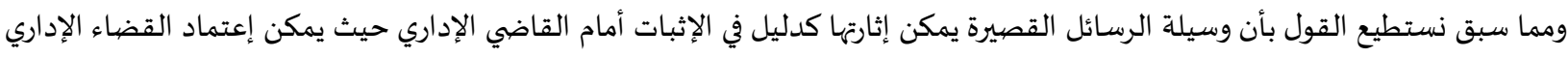

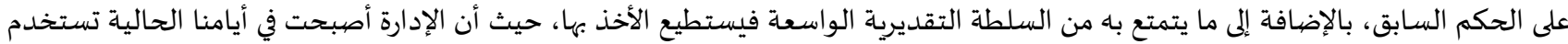
هذه الوسيلة لإرسال ما يحتوي القرار الإداري عبرها للشخص الشع المعني وهو يمكنه الطعن فياه من خلالها.

الخـاتمةة:

انتهينا بفضل الله تعالى من إتمام هذا البحث الموسوم ب " وسائل الإثبات الإلكترونية أمام القضياء الإداري"، فتناولنا من خلاله المحررات

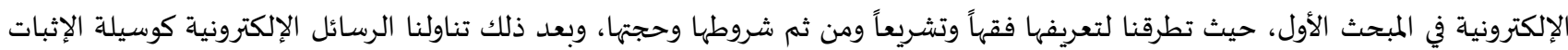
الإداري، في بحثنا في البريد الإلكتروني في المطلب الأول، وفي الفاكس والرسائل القصيرة في المطلب الثاني. وأسفر البحث عن مجموعة من النتائج والتوصيات نود بيانها كئ كما يلي:

عرف المشرع الفرنسي الدليل الكتابي بشكله العام ليشمل جميع الدعامات سواء كانت ورقية أو إلكترونية أو غيرها، بينما وضع المشرع المصري

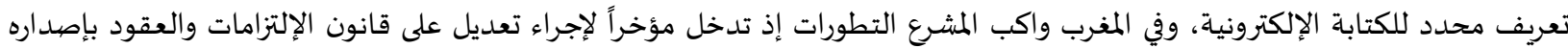
القانون رقم 53:05 والمتعلق بالتبادل الإلكتروني للمعطيات القانونية، فوسع من مفهوم الدليل الكتابي، فنص الفصل

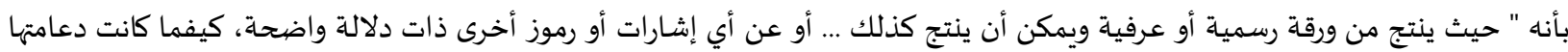
وطريقة إرسالها..."، وعلى العكس من ذلك ذهب المشرع الأردني بطريقة غير مباشرة في تعريفه للدليل الكتابي الإلكتروني، فقد تطرق لعدة مفاهيم

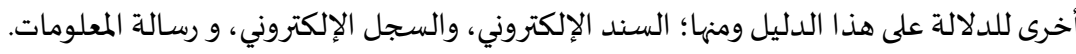

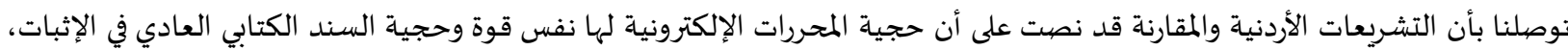

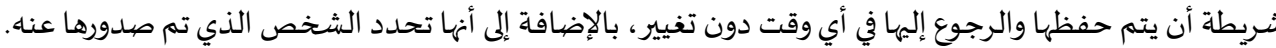
لم نرى أي حكم صادر عن القضياء الإداري وخاصة في الأردن فيما يتعلق بوسائل الإثبات الإلكترونية. إن القاضي الإداري ومن خلال تمتعاه بدور إيجابي وفعال في الإثبات يستطيع اعتماد هذه الوسائل في إثبات الدعوى الإدارية. أما حجية البريد الإلكتروني، لم يتطرق المشرع الأردني لحجية البريد الإلكتروني في القانون المعاملات الإلكترونية، ولكن يوجد نص صريح في قانون البينات الأردني حدد حجيته في المادة 13وعمل على المساواة بينها وبين السندات العادية في الإثبات.

ثانياً: التوصيات:

نوصي بالعمل على تدريب القضاة الإداريين من خلال عقد دورات في كيفية الاستخدام والتعامل مع التكنولوجيا وخصوصاً في مجال الإثبات

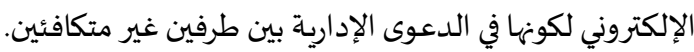

9. د.طارق جمعة السيد راشد، مدى حجية رسائل التواصل الاجتماعي النصية SMS في الإثبات، بحث منشور في مجلة العلوم القانونية والاقتصادية، جامعة عين شمس، مصر، المجلد 58، العدد 2،

80 أشار إليه: د.الحميدي بن ابراهيم بن مرزوق الحميمص، دور الوسائل الإلكترونية في الإثبات أمام القاضي الإداري، مرجع سابق، ص34. 
نوصبي المشرع الأردني في أقرب وقت ممكن في وضع قانون الإثبات الإداري وأن ينظم بين نصوصاه أدلة الإثبات الإلكترونية في القضاء الإداري

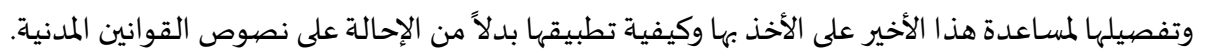

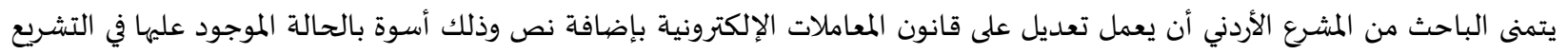

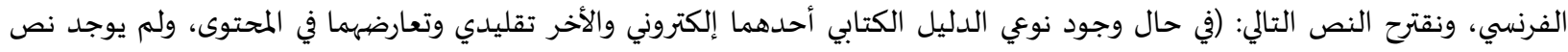

تشريعي ولا إتفاق بين الأطراف، فيحكم القاضي بهذه المسألة بترجيح الدليل الذي يكون أقرب احتمالاً للصحة مهما كانت دعامته المثبت عليها ).

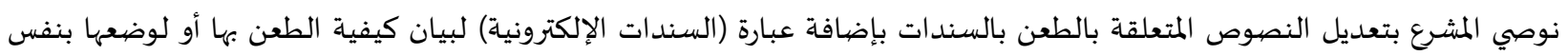
مرتبة الطعن بالسندات التقليدية.

نأمل من المشرع الأردني تعديل المادتين 6 و 7 من قانون المعاملات الإلكترونية وذلك بدمجههما في نص مادة واحدة لأنهما نفس المضهمون إلى حد ما. نوصي المشرع الأردني بتعديل المادة 2 من قانون المعاملات الإلكترونية وذلك بتحديد تعريف للكتابة الإلكترونية كما فعل المشرع المصري والفرنسي لأهها ذات أهمية أكثر من التعريفات الأخرى التي وضعت التهن في تلك المادة.

ضرورة النص صراحة على حجية الكتابة والتوقيع الإلكترونيين في الإثبات الإداري فيما يتعلق بالقرارات والعقود الإدارية، وأن تكون لها حجية

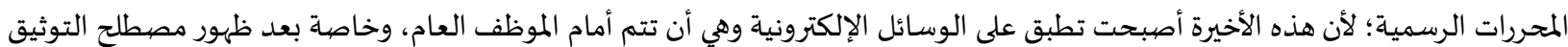
الإلكتروني والموظف الإلكتروني.

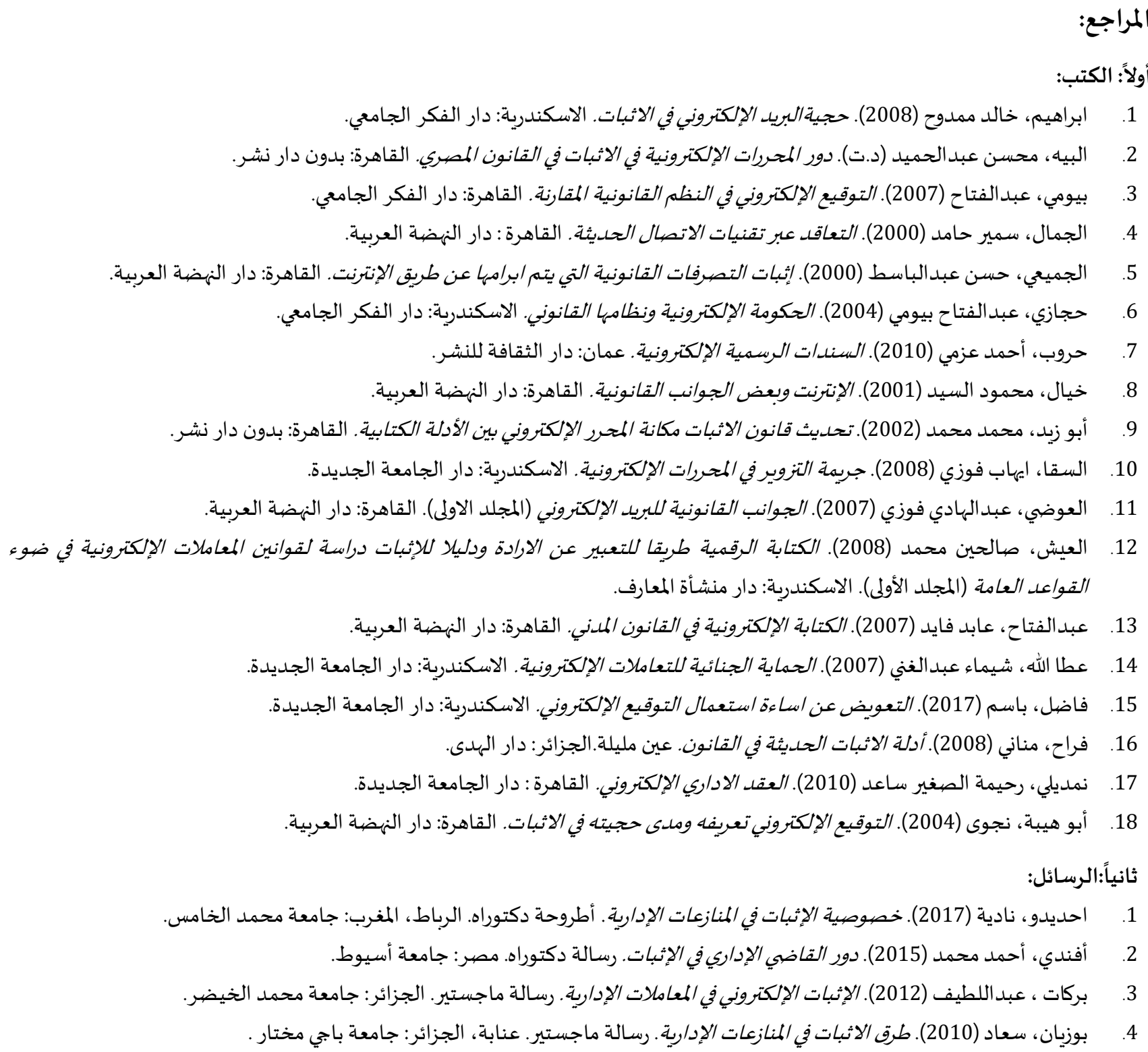


5.

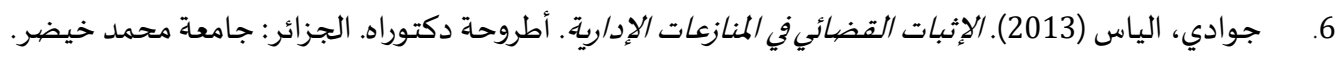
7.

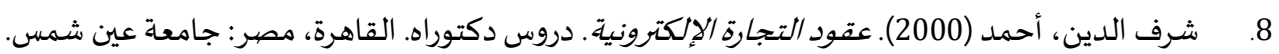

9 .

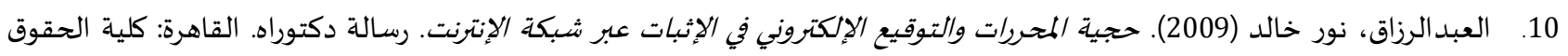

جامعة عين شمس.

11. فروجي، سارة (2014). أدلة الإثبات الحلديثة في المواد الإدرارية. رسالة ماجستير. سكرة، الجزائر: جامعة محمد خيضر.

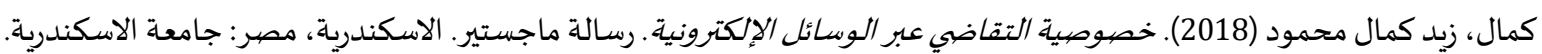
الليل، عائشة قصار (2016). حجية المحرر والتوقيع الإلكتروني في الاثبات. أطروحة دكتوراه. باتنة، الجزائر: جامعة الحاج لخضير.

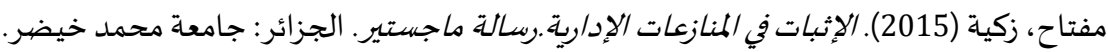

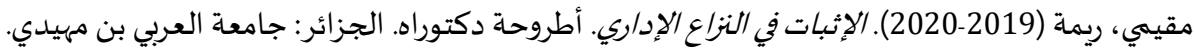
.12 .13 .14 15

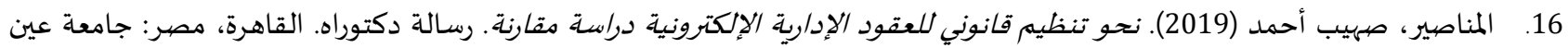

شمس.

ثالثاً: الأبحاث:

1. أنجوم، عمر؛ الحياني، ادريس (2007). إثبات العقد الإلكتروني وفق قانون الالتزامات والعقود وعلى ضيوء مشـووع قانون التبادل الإلكتروني

للمعطيات القانونية. مجلة القانون المغربي: (11).

بدرالدين، هشام عبد السيد الصافي محمد (2017). الدليل الإلكتروني أمام القاضي الإداري. مجلة الحقوق والعلوم السياسية: جامعة زيان عاشور الجلفة، العاشر ( العدد الرابع). حمامدة، أشرف (2018). المحررات الإلكترونية كوسيلة من وسائل إثبات العقد الاد/ري الإلكتروني. مجلة جامعة الاسراء للعلوم الانسانية: (العدد الرابع).

4. الحميمص، الحميدي بن ابراهيم بن مرزوق (2019). دور الوسائل الإككترونية في الإثبات أمام القاضي الإداري. مجلة الفقه والقانون:(80).

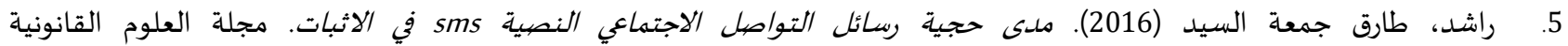
والاقتصبادية.جامعة عين شمس: 58 (2). 6. الراشدي، عزيز (2014). خصبوصية الاثبات في المنازعات الإدارية. مجلة القانون المفربي: (22).

7.

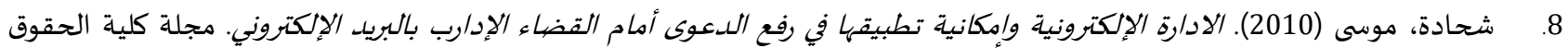

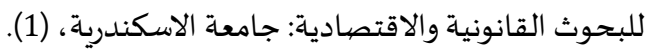
9. الشوابكة، فيصل عبد الحافظ (2013). النظام القانوني للعقد الإد/ري الإلكتروني. مجلة الجامعة الإسلامية للدراسات الاقتصادية والادارية: الحادي والعشرون(العدد الثاني). 10. صاحب، ندى حمزة (2016). الحجية القانونية للمستندات الإلكترونية وطرق الطعن فيها. مجلة لارك للفلسفة واللسانيات والعلوم الاجتماعياة: (الثاني والعشرون).

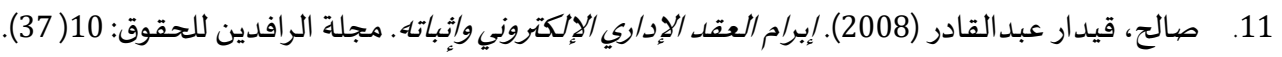

12.

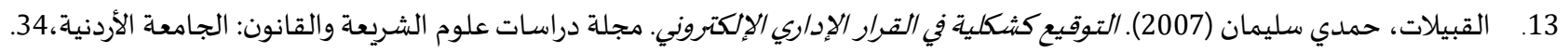
14.

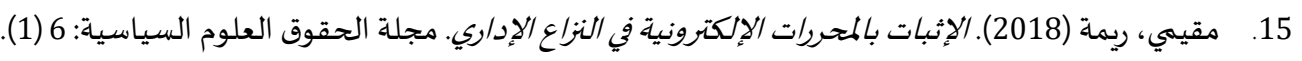
رابعاً: القوانين: 1.

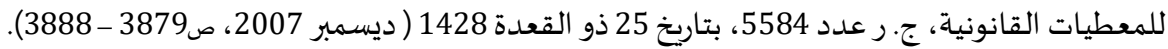

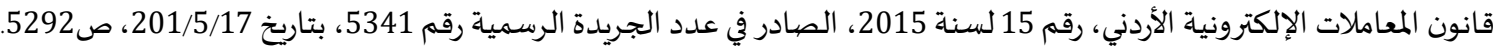


3.

العدد 17 تابع ( د )، بتاريخ 2004/4/22.

\section{خامساً: المراجع الأجنبية:}

1. Caprioli, eric (1999), ;le juge et la preuve électroniaue contribution au colloaue de strasbourg le co,erce électroniaue vers un nouveau droit 8 -9 octobre.Paris: sans éditeur.

2. Lamy .(2001).;informatiaue et des réseax paris: sans éditeur. 


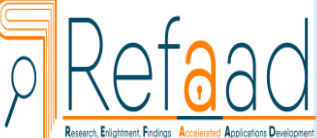

www.refaad.com
المجلة الدولية للدراسات القانونية والفقهية المقارنة

International Journal of Legal and Comparative Jurisprudence Studies (LCJS)

Journal Homepage: https://www.refaad.com/views/LCJS/Home.aspx

ISSN: 2708-6607(Online) 2708-6593(Print)

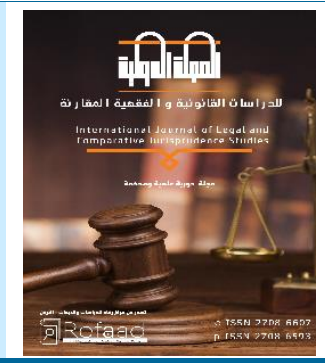

\title{
Electronic means of proof before the administrative court
}

\section{Oday Mohammad Ali Alheilat}

PhD researcher at the Faculty of Law, Ibn Zohr University, Morocco and a trained lawyer at the Jordanian Bar Association odaihailat1991@gmail.com

\author{
Received: 13/6/2021 Revised: 2/8/2021 Accepted: 9/8/2021 DOI: https://doi.org/10.31559/LCJS2021.2.2.4
}

Abstract: The relations between the administration and individuals have been traditional since antiquity until the spread of technology in a large way, so no country can avoid it. The development, which prompted him to invent new means of proof in front of him, which is called electronic proof, including electronic editors and e-mails, and consequently the legislation worked on regulating these means.

Therefore, we will present this topic through electronic editors with their definition and authenticity in the first topic, and then we will look at electronic messages in the second topic, and we ended this research with a set of results, including; We concluded that the Jordanian and comparative legislations stipulate that the authenticity of electronic documents has the same strength and authenticity as the ordinary written document in proof, provided that it is preserved and referenced at any time without change, in addition to that it identifies the person from whom it was issued, and we made several recommendations, the most important of which are; We recommend working on training administrative judges by holding courses on how to use and deal with technology, especially in the field of electronic proof because it is in an administrative lawsuit between two unequal parties.

Keywords: Electronic proof; electronic editor; electronic signature; e-mail; administrative jurisdiction.

\section{References:}

1. Anjwm, 'mr: Alhyany, Adrys (2007). Ethbat Al'qd Alelktrwny Wfq Qanwn Alaltzamat Wal'qwd W'la Dw' Mshrw' Qanwn Altbadl Alelktrwny Llm'tyat Alqanwnyh. Mjlt Alqanwn Almghrby: (11).

2. Bdraldyn, Hsham 'bd Alsyd Alsafy Mhmd (2017). Aldlyl Alelktrwny Amam Alqady Aledary. Mjlt Alhqwq Wal'elwm Alsyasyh: Jam't Zyan 'ashwr Aljlfh,Al'ashr ( Al'edd Alrab'e).

3. Hmamdh, Ashrf (2018). Almhrrat Alelktrwnyh Kwsylh Mn Wsa'l Ethbat Al'qd Aladary Alelktrwny. Mjlt Jam't Alasra' Ll'lwm Alansanyh: (Al'dd Alrab').

4. Alhmyms, Alhmydy Bn Abrahym Bn Mrzwq (2019). Dwr Alwsa'l Alelktrwnyh Fy Alethbat Amam Alqady Aledary. Mjlt Alfqh Walqanwn:(80).

5. Mqymy, Rymh (2018). Alethbat Balmhrrat Alelktrwnyh Fy Alnza' Aledary. Mjlt Alhqwq Al'lwm Alsyasyh: 6 (1).

6. Alqbylat, Hmdy Slyman (2007). Altwqy' Kshklyh Fy Alqrar Aledary Alelktrwny. Mjlt Drasat 'lwm Alshry'h Walqanwn: Aljam'h Alardnyh,34.

7. Qnfwd, Rmdan (2018). Altby'h Alqanwnyh Llbryd Alelktrwny Wmda Hjyth Fy Alathbat. Mjlt Aldrasat Alqanwnyh: 3 (2).

8. Rashd, Tarq Jm'h Alsyd (2016). Mda Hjyt Rsa'l Altwasl Alajtma'y Alnsyh Sms Fy Alathbat. Mjlt Al'lwm Alqanwnyh Walaqtsadyh. Jam't 'yn Shms: 58 (2).

9. Alrashdy, 'zyz (2014). Khswsyh Alathbat Fy Almnaz'at Aledaryh. Mjlt Alqanwn Almghrby: (22).

10. Sahb, Nda Hmzh (2016). Alhjyh Alqanwnyh Llmstndat Alelktrwnyh Wtrq Alt'n Fyha. Mjlt Lark Llflsfh Wallsanyat Wal'lwm Alajtma'yh: (Althany Wal'shrwn).

11. Salh, Qydar 'bdalqadr (2008). Ebram Al'qd Aledary Alelktrwny Wethbath. Mjlt Alrafdyn Llhqwq: 10(37). 
12. Abw Sbah, Ahmd: Alsrayrh, Abrahym (2020). Ethbat Al'qd Aledary Alelktrwny. Mjlt Jam't Alnjah Ll'lwm Alansanyh: 34 (7).

13. Shbyr, Mhmd Slyman (2017). Alnzam Alqanwny Llbryd Aledary Alelktrwny. Mjlt Jam't Alazhr: 19 ('dd Khas).

14. Shhadh, Mwsa (2010). Aladarh Alelktrwnyh Wemkanyh Ttbyqha Fy Rf' Ald'wa Amam Alqda' Aledarb Balbryd Alelktrwny. Mjlt Klyt Alhqwq Llbhwth Alqanwnyh Walaqtsadyh: Jam't Alaskndryh, (1).

15. Alshwabkh, Fysl 'bdalhafz (2013). Alnzam Alqanwny Ll'qd Aledary Alelktrwny. Mjlt Aljam'h Aleslamyh Lldrasat Alaqtsadyh Waladaryh: Alhady Wal'shrwn(Al'dd Althany). 